\title{
Manufacturing TECHNOLOGIES
}

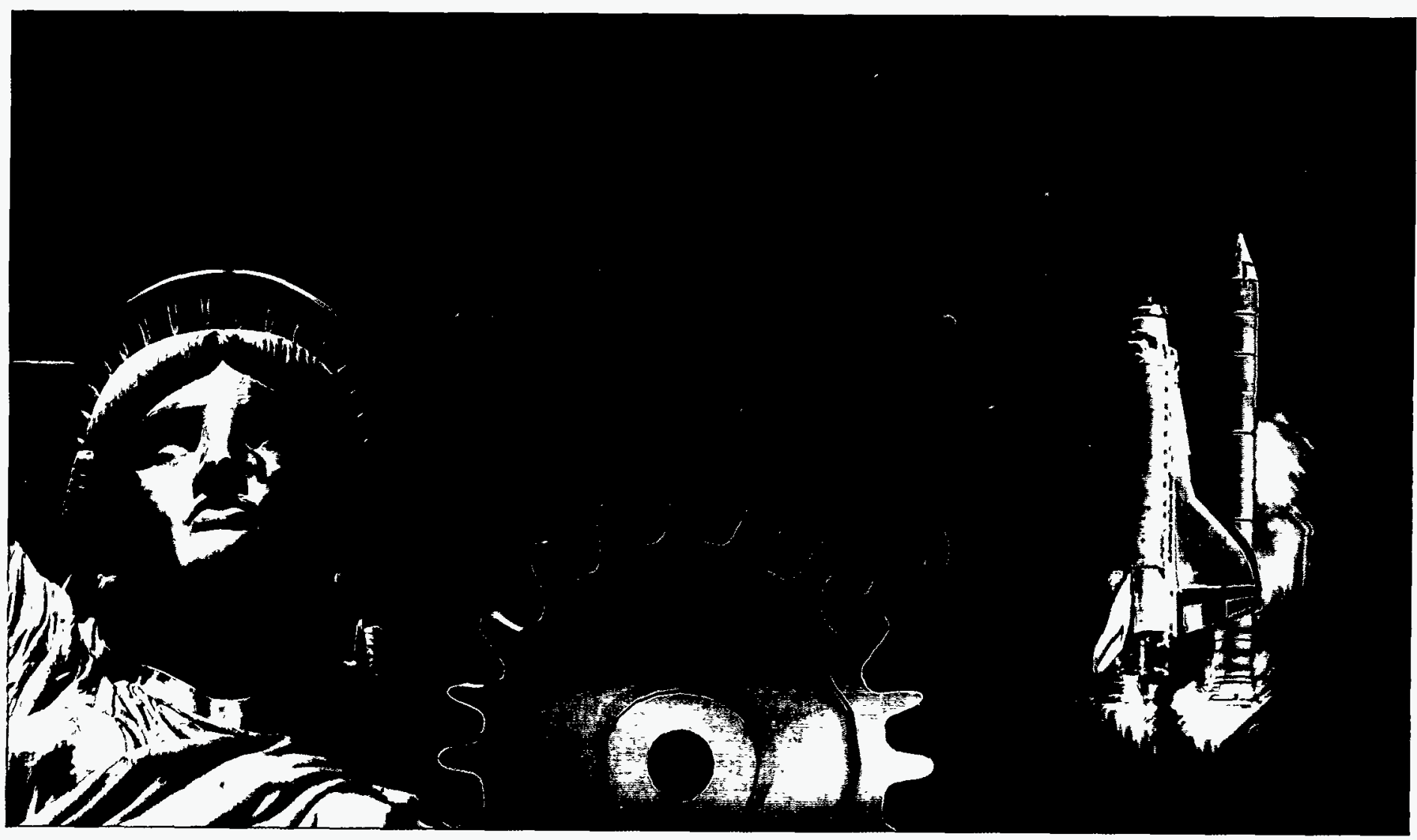

\section{DISCLAIMER}

This report was prepared as an account of work sponsored by an agency of the United States Government. Neither the United States Government nor any agency thereof, nor any of their employees, makes any warranty, express or implied, or assumes any legal liability or responsibility for the accuracy, completeness, or usefulness of any information, apparatus, product, or process disclosed, or represents that its use would not infringe privately owned rights. Reference herein to any specific commercial product, process, or service by trade name, trademark, manufacturer, or otherwise does not necessarily constitute or imply its endorsement, recommendation, or favoring by the United States Government or any agency thereof. The views and opinions of authors expressed herein do not necessarily state or reflect those of the 


\section{INTRODUCTION}

The Manufacturing Technologies Center is an integral part of Sandia National Laboratories, a multiprogram engineering and science laboratory, operated for the Department of Energy (DOE) with major facilities at Albuquerque, New Mexico, and Livermore, California. Our Center is at the core of Sandia's Advanced Manufacturing effort which spans the entire product realization process.

\section{WHAT WE DO}

Our mission is to make customers successful through excellence in the manufacturing disciplines. We focus on the manufacturing needs of Sandia's Defense, Work for Others, and Energy and Environment Sectors, while improving U.S. industrial competitiveness. We work for continuous improvement through the application of quality principles striving to deliver goods and services that consistently exceed customer expectations. We are dedicated to satisfying the cost, schedule and performance requirements of our internal and external customers.

Our capabilities in product and process development, listed here, and described in the accompanying literature, include:

\section{Mechanical}

- Rapid Prototyping

- Manufacturing Engineering

- Machining \& Computer-Aided Manufacturing

- Measurement \& Calibration

- Mechanical \& Electronic Manufacturing Liaison
Electronics

- Microelectronics: Advanced Packaging

- Printed Circuits

- Electronic Fabrication

\section{Materials}

- Ceramics

- Glass

- Thin Film, Vacuum, \& Brazing

- Polymers, Adhesives \& Composites

- Process Analysis

\section{WORKING WITH U.S. INDUSTRY}

Sandia's approach is to concentrate on programs that add value to the nation, exercise and strengthen our core technical competencies and integrated capabilities. As a designated Technology Deployment Center and User Facility, the Manufacturing Technologies Center encourages joint research and development activities with industry, universities, and other government entities. Other technology transfer mechanisms include: Cooperative Research and Development Agreements (CRADAs), Licensing, Small Business Technical Assistance, and Work for Others (WFO).

For more information on how you can partner with Sandia, contact John Sayre at (505) 845-9757, email at jasayre@sandia.gov or Carla Chirigos at (505) 845-8645, email at cdchiri@sandia.gov. 


\section{DISCLAIMER}

Portions of this document may be illegible in electronic image products. Images are produced from the best available original document. 


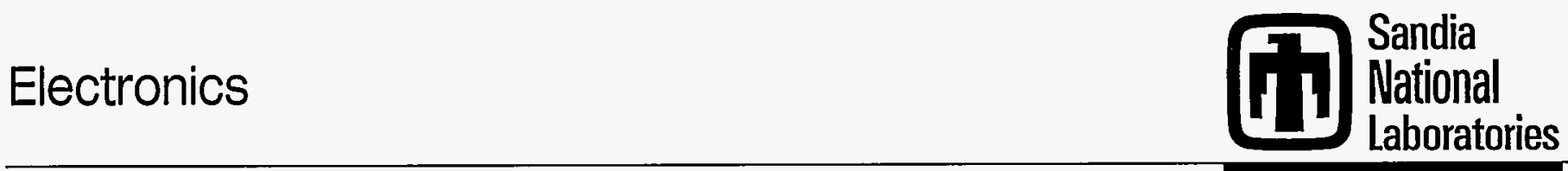

\section{Microelectronics: Advanced Packaging}

The Sandia National Laboratories' Hybrid Microcircuit group is a resource for all aspects of hybrid microcircuit and flat panel engineering. From design and layout to actual fabrication of prototype samples, we offer partners the opportunity for concurrent engineering and development of hybrid Multi-Chip Modules (MCMs) and soft substrate network designs. This includes assistance in selecting the most appropriate technology for manufacturing and analysis of performance characteristics.

Hybrid microcircuits and flat panels are electronic circuits that interconnect both active and passive devices on a variety of substrate materials. The most recent substrate characterized is diamond. Hybrid microcircuits can be multilayer thick- or thin-film circuits with monolithic resistors and capacitors fabricated on the surface. This allows construction of precise circuits for advanced applications such as impedance matching high frequency circuits. An important advantage of hybrid microcircuits is low weight, small volume, and high density of electronic circuitry and components.

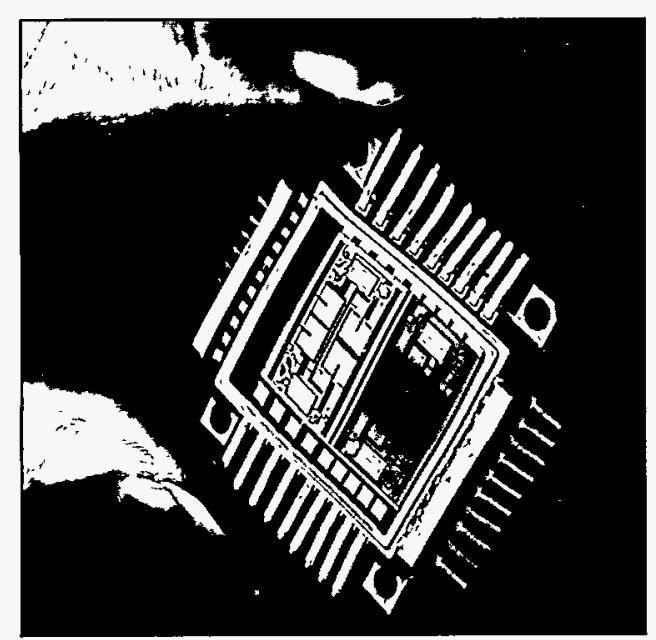

Flat panel substrates are similar in many processes except that they are much larger. Challenges in this field include fabrication of more costeffective devices, using robust materials and processes, and smaller conductor feature size. These devices must be manufactured using environmentally conscious processes.

\section{Capabilities}

The ability to manufacture and test hybrid microcircuits and flat panels is possible through our expertise in the following technologies:

- Thick-film multilayer double-sided hybrids.

- Thin-film hybrids.

- Chip and wire hybrids.

- Low-temperature co-fired ceramic three-dimensional packages.

- Hybrids built on Duroid ${ }^{\oplus}$ substrates.

- Semiconductor device packaging.

- Screen printing or plating to produce fine-line panels.

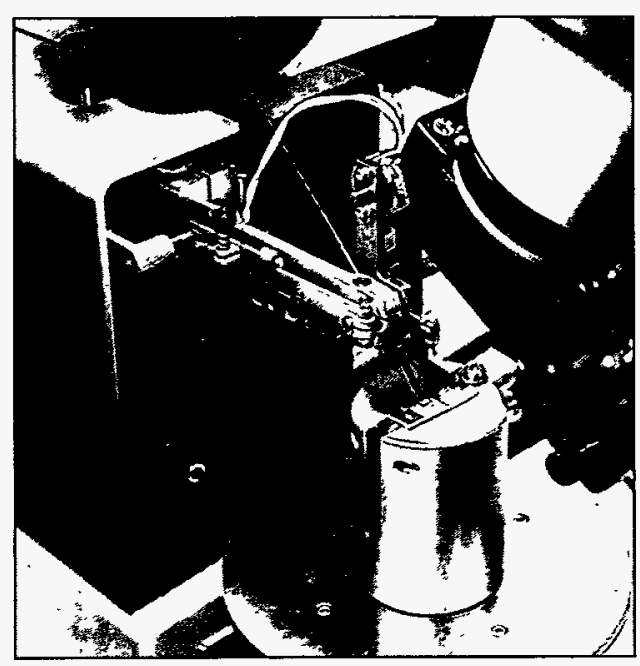

High power circuits require large diameter wire such as this $10 \mathrm{mil}$ aluminum wire.

\section{Major Resources}

- Staff trained in project support across a wide spectrum of hybrid microcircuit technologies.

- A complete set of manufacturing equipment, for thick- and-thin film hybrid fabrication including a directwrite $\mathrm{Micropen}^{\circledast}, \mathrm{CO}_{2}$ and $\mathrm{YAG}$ lasers, dc magnetron vacuum coaters, via filling machines, and an isostatic press for fabricating cofired ceramic structures.

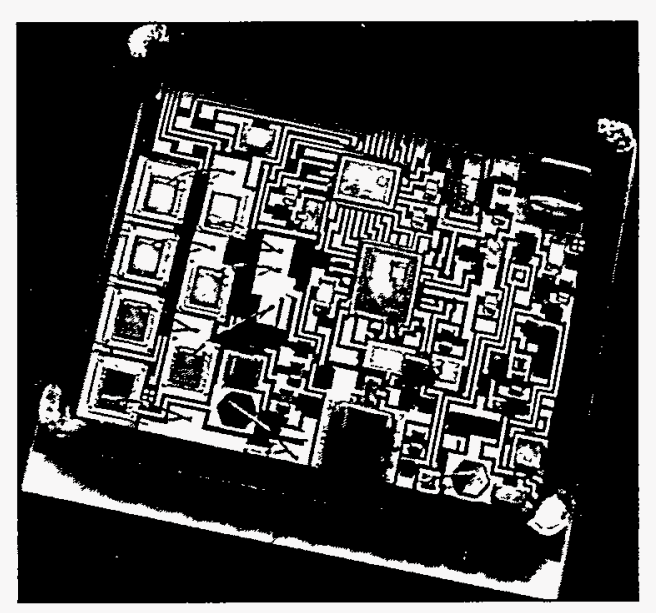

A high temperature automotive underhood Multi-Chip Module.

\section{Selected Accomplishments}

- Developed circuits on diamond substrates for electronics requiring extreme thermal dissipation.

- Developed deposition process for monolithic capacitors on substrates.

- Established a non-Freon process utilizing downstream plasma processing for cleaning prior to wire bonding.

- Evaluated packaging technologies for die attach materials, wire bond reliability, and hermetic sealing of electronic circuits subjected to extreme temperature, atmospheres, mechanical shock, and vibration.
Diamond has been evaluated and tested as a hybrid substrate in this Multi-Chip Module circuit. 


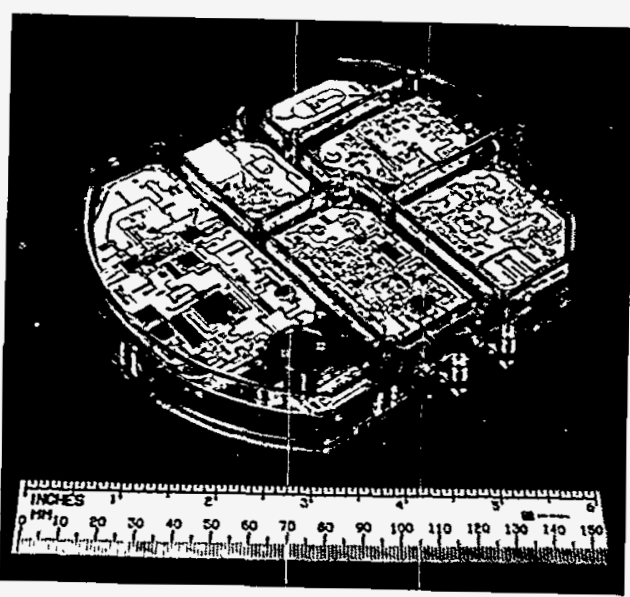

The precision patterning available using photolithographic processes on thin-film networks is well suited to the fabrication of high-performance radars.
- Manufactured microwave hybrids for use in Synthetic Aperture Radar (SAR) at frequencies up to $15 \mathrm{GHz}$ on Duroid ${ }^{\circledR}$ substrates. Patterning was demonstrated to 6 micron tolerances on 17 micron copper conductors. The hybrids contained through-hole and slot vias as well as component cavities for Monolithic Microwave Integrated Circuit (MMIC) devices.

- Established fine-line additive precious metal plating process for large glass substrates.

For more information, call

Gerald L. Cessac

(505) 845-9199, or

Carla Chirigos

(505) 845-8645.

\section{DISCLAIMER}

This report was prepared as an account of work sponsored by an agency of the United States Government. Neither the United States Government nor any agency thereof, nor any of their employees, makes any warranty, express or implied, or assumes any legal liability or responsibility for the accuracy, completeness, or usefulness of any information, apparatus, product, or process disclosed, or represents that its use would not infringe privately owned rights. Reference herein to any specific commercial product, process, or service by trade name, trademark, manufacturer, or otherwise does not necessarily constitute or imply its endorsement, recommendation, or favoring by the United States Government or any agency thereof. The views and opinions of authors expressed herein do not necessarily state or reflect those of the United States Government or any agency thereof. 


Electronics

\section{Printed Circuits}

The Sandia National Laboratories' Printed Circuit group offers a technology base for the design, development, and production of electrical interconnection devices using polymer based laminates, printed circuit boards, multi-chip modules, flex circuits, rigid-flex devices, and chemically milled metal foil products. Possibilities in this area include:

- Manufacture of large area patterned substrates with fine lines and spaces, conductor uniformity, and high yield.

- Rapid drilling of holes down to 3 to 6 mils in substrates to accommodate the increasing density of electronic packages.

- Developing processes which are environmentally conscious and cost effective.

The technologies that we have developed in collaboration with our industry partners for process

improvement of fine line cabability will soon become an industry standard. Numerous test panels can be generated which include multi-line, multi-space, and single pitch in order to evaluate inner layer processes for the printed wiring board industry.

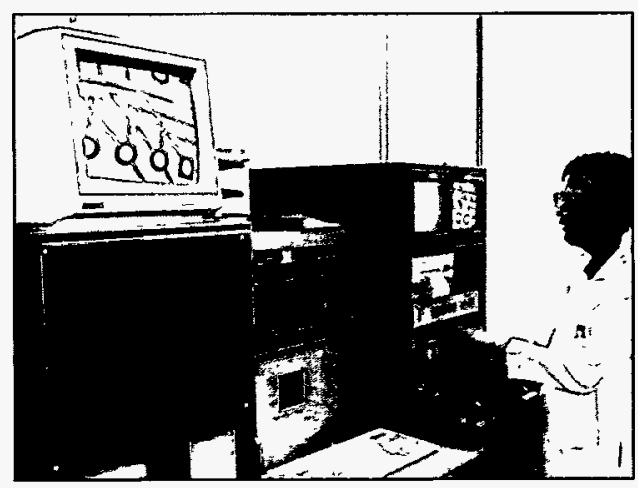

$X$-ray diagnostic tool used to pinpoint faults on inner layers of circuit boards.

\section{Capabilities}

Develop, facilitate, assemble, and test multilayer printed circuit boards, flex circuits, and rigid-flex devices.

- Environmentally test electronic subsystems, perform x-ray inspection, and test bare boards.

- Provide assembly functions including: screen printing, wave and vapor phase soldering, aqueous cleaning, and microwelding.

- Unique implementation of waste reduction and copper recovery systems.

- Prototype design of laminate based substrates.

\section{Major Resources}

- Staff provides project support from design to manufacture across a wide spectrum of printed circuit technologies.

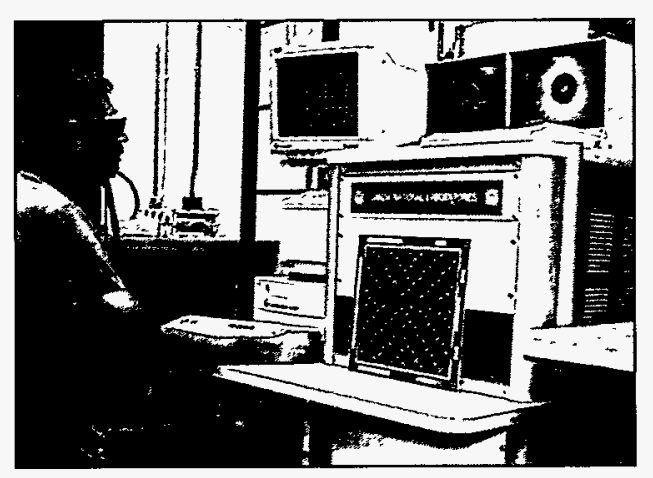

Tester for precision resistance measurements of conductors.

- Gerber Photoplotter with accompanying workstation that can generate artwork features 0.0005 inch or greater with a maximum film size of $20 \times 26$ inches.

- Integri-Test bare board tester.

- Astrophysics Research Corporation $\mathrm{x}$-ray inspection system.

- System for rapid measurements of conductor resistance which allows real-time process improvement.

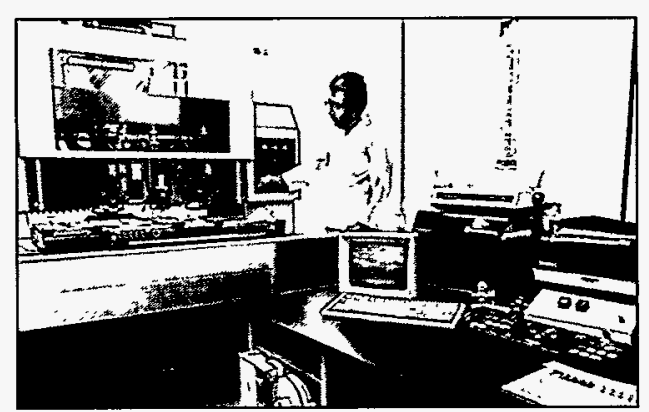

Numerically controlled drill.

- Laser drill which can drill blind vias in the .004 inch range at a rate of 400 holes per minute.

- Assistance with selecting the most appropriate material and packaging technology.

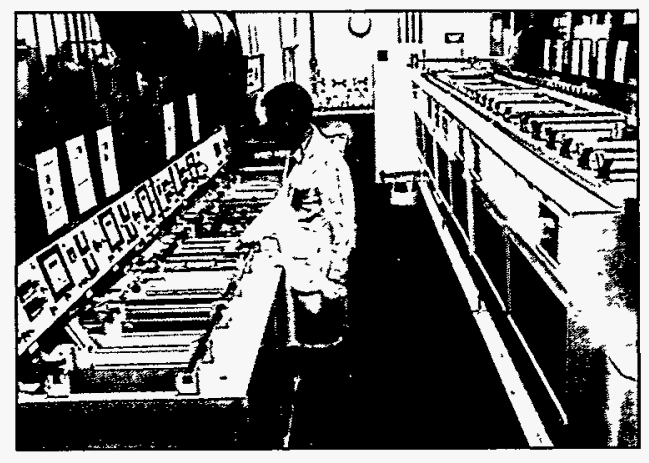

New automated plating line.

\section{Selected}

\section{Accomplishments}

- Developed processes for plating copper onto Duroid ${ }^{\circledR}$ substrates.

- Established process capability for fine line imaging down to 2 mil lines and spaces.

- Demonstrated a copper recovery system for dilute rinse waters to enhance environmentally conscious manufacturing.

- Developed a Conductor Analysis Tester (CAT) using a unique switching mechanism for rapid resistance measurement on conductor patterns of test panels. 


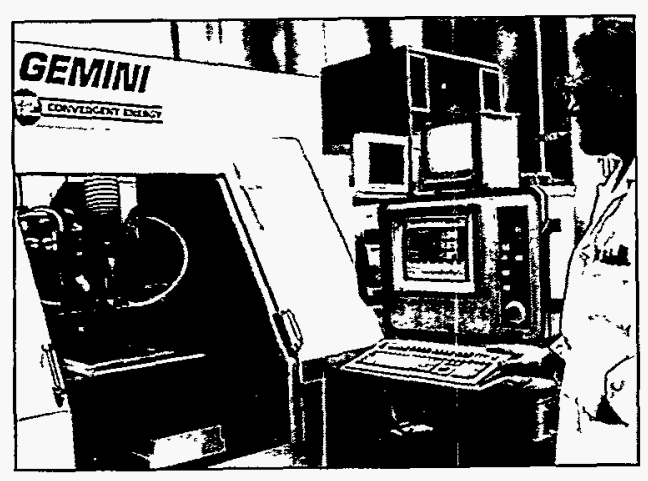

Laser drill for drilling blind vias.
- Developed processing methods for electroplating black coatings on solar applications.

- Developed heat-absorbing ablative coatings to rocket bodies.

- Developed organic powder coatings that can withstand corrosive environments.

For more information, call

Gerald L. Cessac

(505) 845-9199, or

Carla Chirigos

(505) 845-8645. 


Eactorise

\section{ELECTRONIC FABRICATION}

The Sandia National Laboratories' Electronic Fabrication Group offers a variety of hardware and software needs for unique applications. Our expertise spans every aspect of the electronic manufacturing process including:

- Electronic System Design.

- Software/Analog/Digital Design.

- Electronic Prototype Fabrication.

- Electrical Inspection.

- Magnetic Device Fabrication.

\section{Capabilities}

- Concurrent engineering in prototype fabrication.

- Engineering consultation in software design and data acquisition systems.

- Review of electronic packaging drawings, design, and inspection requirements.

- Complete inspection services for electronic packaging per MIL-STD 2000 and industry standards.

- Manufacturing and packaging of unique electrical designs.

- Customer assistance with complete systems assembly, installation, and final product testing.

- Computer-aided winding of transformers, toroids and precision resistors with inspection before and after encapsulation.

- Winding capabilities of ultrafine (AWG55) to heavy-duty wire (AWG 2).

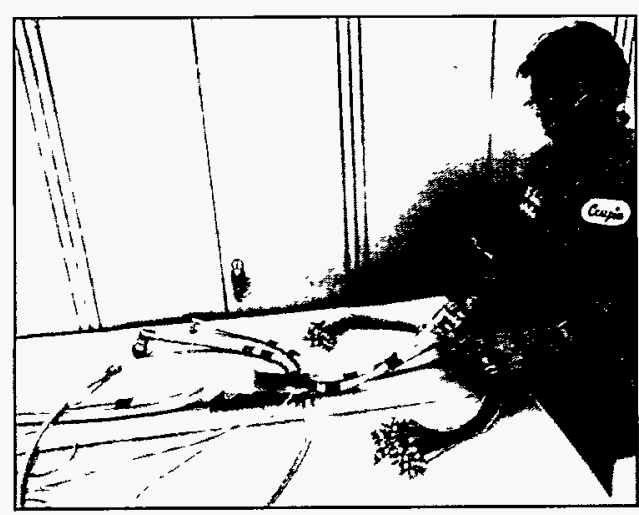

Inter-stage flight cable fabricated and tested in our laboratory.
- Machining unique or commercially unavailable bobbins or winding forms.

- Instructors and technicians certified to soldering MIL-STD 2000 and SNL 9913000 .

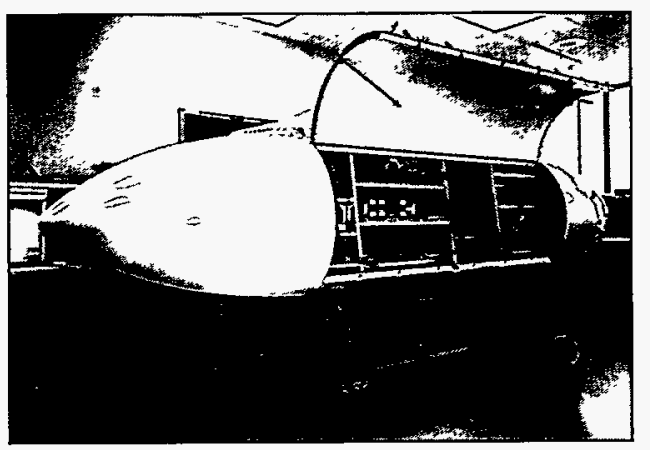

Synthetic Aperture Radar (SAR) Pod is an example of a tradesperson teaming with an engineer on project packaging from conception to a manufacturable prototype.

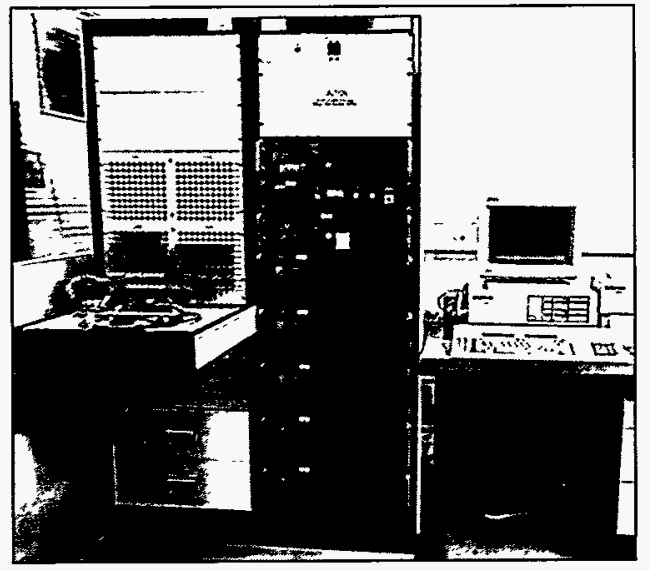

Computer-controlled cable tester performs continuity tests with 1 mohm resolution to identify bad solder joints.

\section{Major Resources}

- Computer-controlled layered and toroid winding machines.

- Engraver capable of receiving electronic files over the Internet and producing engraved panels.
- SE3262 Cable Tester utilized for $100 \%$ electrical inspection of complex cables. The system can measure inter-conductor isolation up to $500 \mathrm{VDC}$, identify conductor size of internal wires, and scan unknown cable configurations and print out point-to-point path of complex cable assemblies.

- Self-contained machine shop for mechanical fabrication of electronic packages.

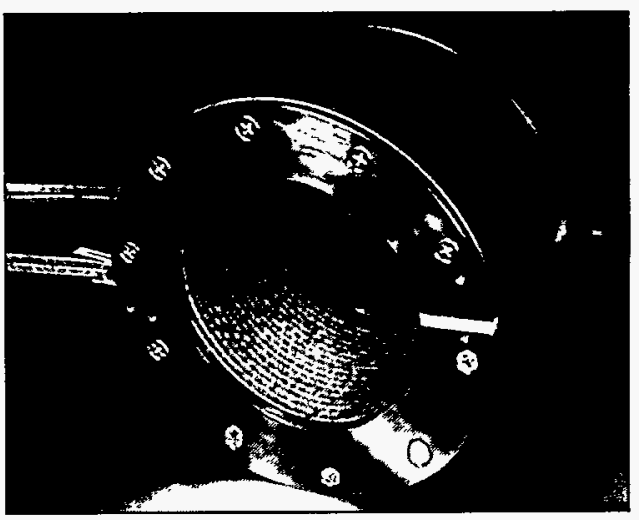

The process for developing and fabricating this coil (used in a prototype cylindrical launcher) was developed through a teaming effort of Sandia engineers and our tradespeople.

\section{Selected \\ Accomplishments}

- Designed and built computercontrolled electrical testers that provided liquid-to-liquid thermal shock or thermal cycling.

- Designed and built a tester to measure Seebeck characteristics of thin-film metallization.

- Designed the hardware and operational software for the Waste Isolation Pilot Plant related projects. These systems are used to control and acquire data during the calibration of rock mechanics and humidity transducers for underground permeability tests. 


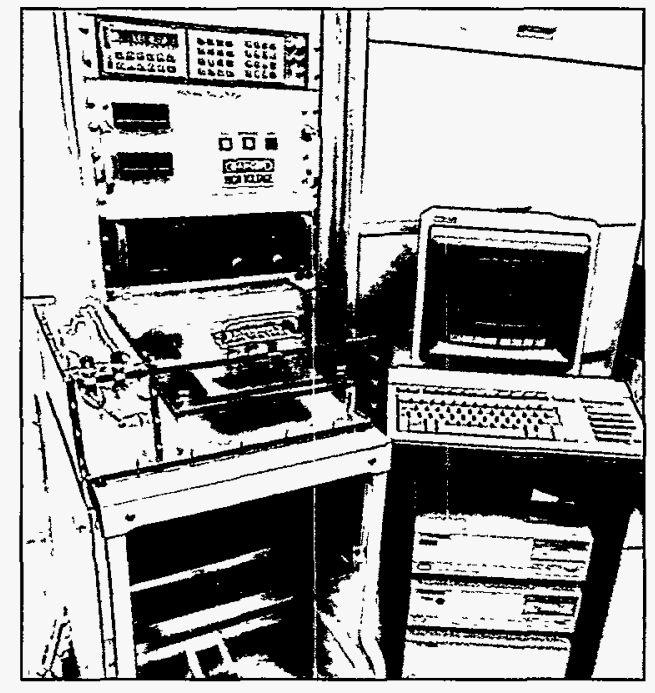

Computer-controlled, user friendly, data acquisition system is one of several custom designed, programmed and fabricated per customer requirements through concurrent engineering.
- Provided Electronic Fabrication support to the Area III Melting Lab for an electron beam furnace. Implemented procedures to test critical operating components.

- Designed and manufactured a Conductor Analysis Tester to measure the resistance of conductors formed on printed wiring board substrates.

- Designed and manufactured a Dielectric Breakdown High Voltage Tester to measure voltage breakdown (up to $20 \mathrm{KVDC}$ ) of thin materials (520 mils).

For more information, call

Phillip L. Gallegos

(505) 844-2445, or

Carla Chirigos

(505) 845-8645.

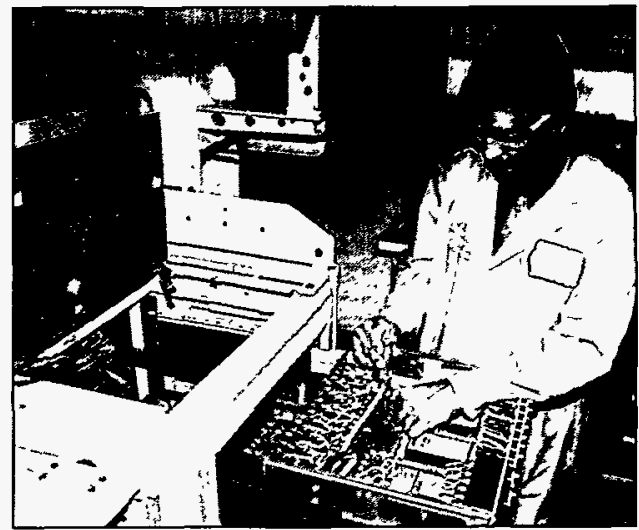

Prototype fabrication and manufacture of a Physical INventory PALlet (PINPAL). This remote controlled device is used for conducting inventory in high radiation areas. 


\section{Thin Film, VacuUm, and Brazing}

The Sandia National Laboratories Thin Film, Vacuum, and Brazing Team works with partners to apply technology in areas that include vacuum system engineering and manufacturing, sealed ultra-high vacuum high voltage devices, flat panel displays, sensors, satellites, and other space applications. We have broad ranging expertise in deposition processes including physical vapor and chemical vapor.

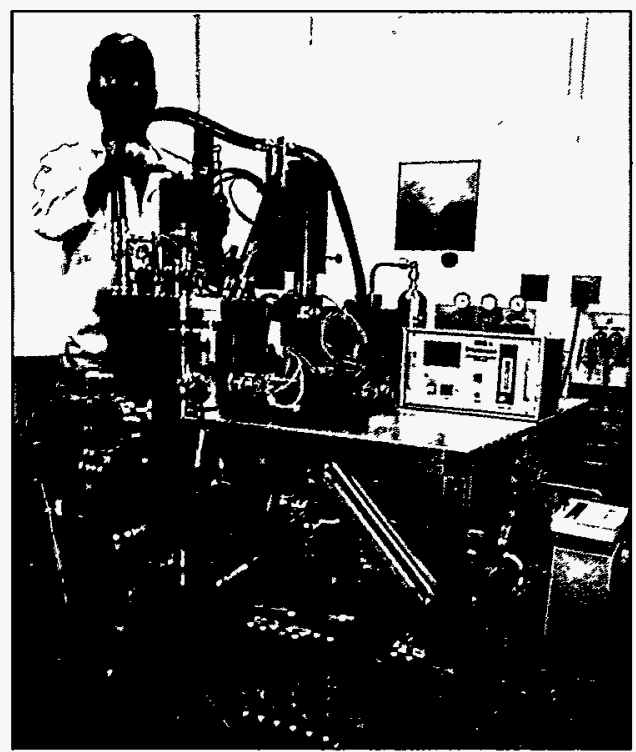

Electron beam evaporator state-ofthe-art computer controlled thin film deposition system.

Our brazing, bonding, and joining technologies, as well as use of vacuum expertise and equipment can advance electronics manufacturing processes. Additionally, the Thin Film, Vacuum, and Brazing Laboratory's unique hardware is available for the development of new processes as well as prototype production. We have fabricated short-term, low volume prototypes using thin-film deposition and brazing for satellite hardware, high-vacuum devices, and the fusion energy program. Specifically, we:

- Deposit many types of thin-films for a broad range of hardware and components using processes such as electron beam evaporation, resistance evaporation, DC and RF magnetron sputtering.

- Join metals by brazing, soldering, and diffusion bonding in vacuum, hydrogen, and inert atmospheres.

- Metallize ceramic surfaces for metalto-ceramic bonding to form metallurgical barriers, and provide compatibility with mating surfaces.

- Engineer, manufacture, and improve the performance of vacuum systems and processing tools.

- Clean metal and ceramic surfaces for vacuum devices by chemical processes, vapor degreasing, and high temperature firing in vacuum, hydrogen, and inert gases.

- Provide short-term prototype fabrications (including specialty fixture development) for unique applications in vacuum, thin film, and brazing.

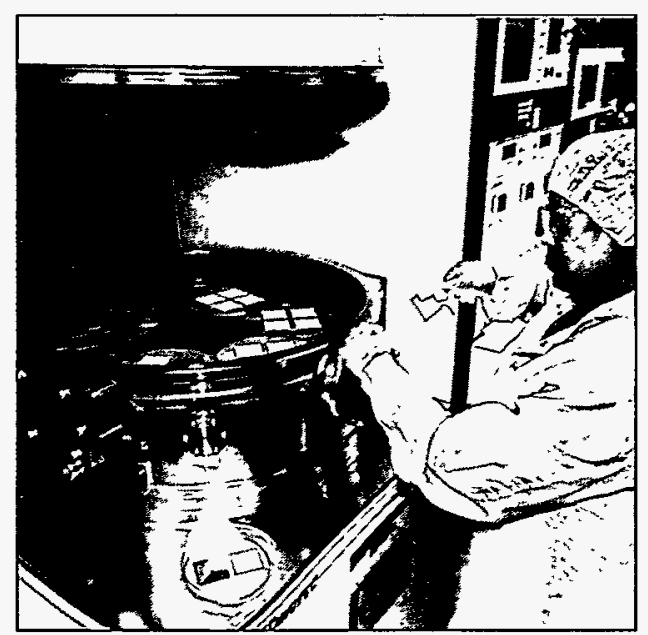

Sputtering systems for prototype thin films.

\section{Capabilities}

- Routinely deposit over 25 elements as well as numerous compounds, glasses, and metal oxides.

- Deposit diamond-like carbon, $\mathrm{SiO}_{2}$ films, and optical quality coatings.

- Employ wet and dry hydrogen and inert gas processing furnaces for state-of-the-art brazing and metal oxide reduction up to temperatures of $2000^{\circ} \mathrm{C}$, particularly for stainless steels, nonferrous materials, hightemperature alloys, and refractory metals.

- Use high-vacuum ( $10^{-7}$ torr) furnaces for treatments up to $1800^{\circ} \mathrm{C}$.

- Perform special bonding operations (such as field-assisted bonding and unique soldering processes).

- Utilize processing workstations with better than Class 1000 clean room conditions for thin-film fabrication that require high purity and contamination control.

- Engineering expertise to manufacture unique furnaces, deposition, and vacuum systems to meet specific customer requirements including design, fabrication, instrumentation, and control.

- Analyze desorption of materials under vacuum (10-10 torr) at $1000^{\circ} \mathrm{C}$ and higher, potentially at temperatures up to $2200^{\circ} \mathrm{C}$.

- Manufacture vacuum gauges and other vacuum instrumentation for unique applications.

- Design and manufacture fixtures for brazing and high-temperature treatments.

- Deposit optical interference coatings.

- Deposit multi-element electrical contacts on semiconductors.

\section{Major Resources}

- Radio frequency and direct current (diode and magnetron) sputter deposition systems.

- Physical vapor deposition systems using electron beam and resistive thermal evaporators.

- High-vacuum ( $10^{-7}$ torr), wet and dry hydrogen, and inert gas processing furnaces.

- Better than Class 1000 clean room for deposition processes that require high purity and contamination control.

- Ultra-high vacuum and controlied atmosphere diffusion bonding systems.

- Class 1000 system assembly area. 


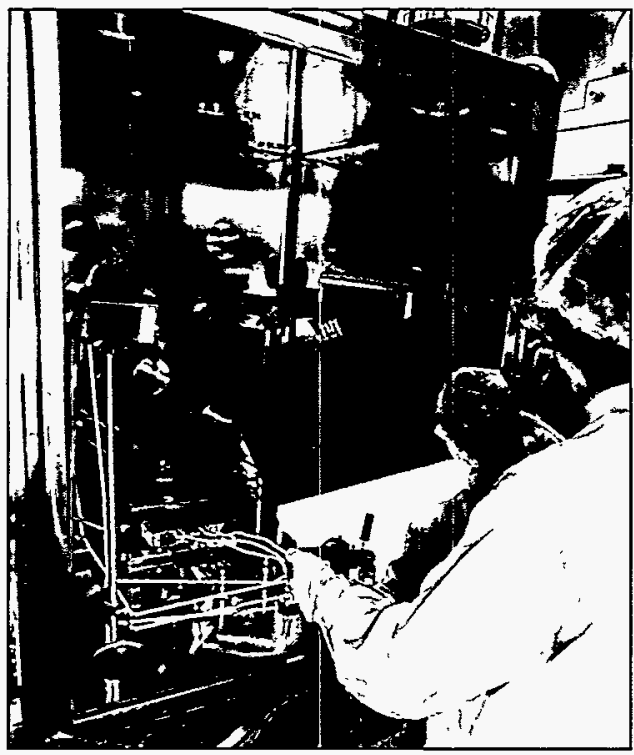

Large area optical coating physical vapor deposition system.

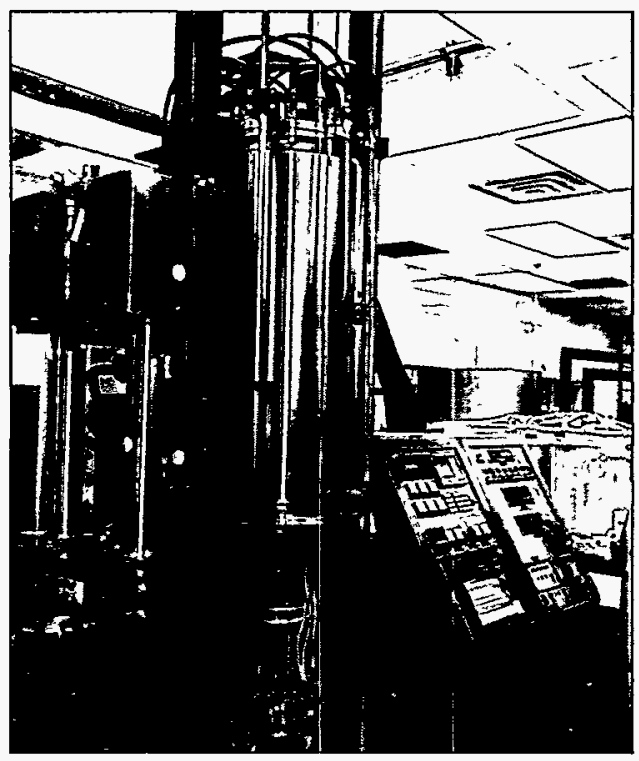

High temperature $\left(2050^{\circ} \mathrm{C}\right)$ controlled atmosphere furnace used to densify cermets.
- Ultra-high vacuum material outgassing analysis system.

- Ultra-high vacuum and controlledambient hot presses with a temperature range up to $1500^{\circ} \mathrm{C}$ and five tons of force.

- Ultra-high vacuum system with ion beam sputtering and surface modification capability. Substrate and target rotation possible with maximum substrate size of 4 inches in diameter.

\section{Selected \\ Accomplishments}

- Engineered and fabricated 1,000,000 liter/second cryocondensation vacuum pump for an inertial confinement fusion accelerator program.

- Fabricated infrared optical interference coating for low observable applications.

- Fabricated free-standing threedimensional thin-film structures that function as targets for Sandia's Particle Beam Fusion Accelerator II (inertial confinement fusion program).

- Deposited multi-element contacts on semiconductors.

- Deposited optical coatings that improve the efficiency of flat panel displays.

- Measured and analyzed the gas composition of flat panel displays to determine aging phenomena.

- Manufactured ultra-high vacuum deposition and bake out systems for the fabrication of vacuum, highvoltage devices.

- Manufactured a high vacuum system used to deposit thin films of highly enriched uranium oxide.

- Manufactured a high vacuum system that characterizes the performance of phosphors used in flat panel displays.

For more information, call John L. Ledman (505) 845-8544, or Carla Chirigos (505) 845-8645.

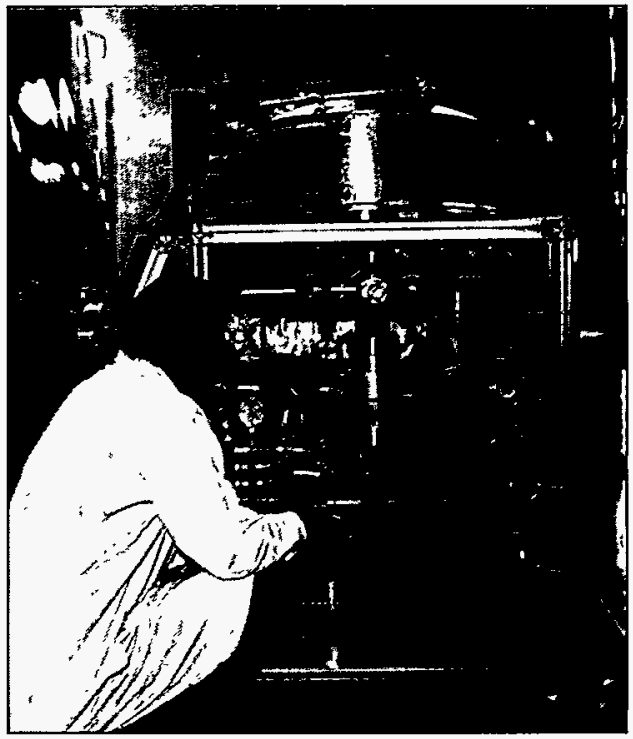

Multi-station bake out system capable of processing devices to $500^{\circ} \mathrm{C}$ and $10^{-10}$ Torr, designed and built by Sandia. 


\section{Polymers, Adhesives, AND CoMPOSITES}

The Sandia National Laboratories' Polymers, Adhesives and Composites Laboratory is a resource for partners needing innovative prototype fabrication, materials technology, and processing expertise. We use thermosetting, thermoplastic, and composite materials to join, package, and provide structural support in the most demanding of applications, such as:

- Packaging and encapsulation of high voltage components.

- Formulation of materials for demanding environments.

- Development of adhesive joining techniques for difficult materials.

- Microelectronics packaging.

To understand the mechanisms for successful bonding and encapsulation, we have developed testing techniques for adhesive joints, metal-to-composite joints, torsion testing of adhesive bonds, and encapsulation resins. In addition, we have formulated new materials which reduce or eliminate the environmental, safety, and health hazards associated with certain polymer processes and compounds.

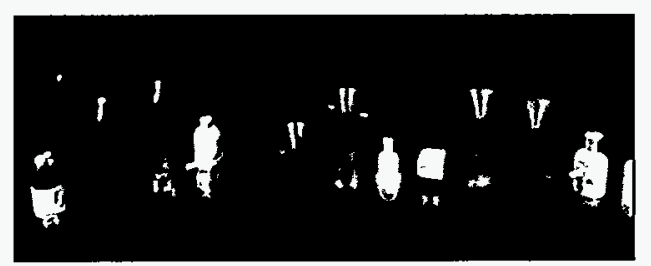

Environmentally conscious encapsulant development for high voltage components.

\section{Capabilities}

\section{- Formulation}

We tailor epoxy, silicone, and polyurethane resin systems for use as encapsulants, adhesives, and sealants to ensure performance of electro-mechanical assemblies in high-voltage, high-impact, and thermal fatigue environments.
- Cleaning/Surface Preparation We perform surface preparation by chemical and plasma cleaning, sandblasting, etching, and priming.

\section{- Thermoforming}

We thermoform a variety of thermoplastic materials such as polycarbonate, polymethyl methacrylate, polypropylene, and polystyrene.

\section{- Bonding}

Our bonding operations employ anaerobic, aerobic, and UV curing methods on many different geometries.

\section{- Coating}

We protect printed circuit boards from dirt, moisture, and other contaminants through the following coating options - epoxies, urethanes, and silicones using spray, brush, or dipping techniques.

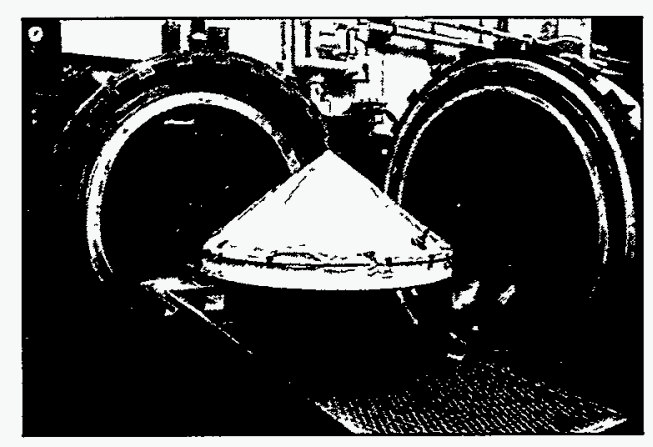

An autoclave with the antenna, described in the "Selected Accomplishments" section.

\section{- Encapsulating}

For electronics and electromechanical assemblies we use foams, elastomers, and rigid resins such as epoxies, silicones, and polyurethanes to protect electrical devices from shock and vibration, to provide rugged protection to testing equipment, and to provide long service life.

\section{- Milling}

We can perform rubber milling of all types of elastomers such as silicones, butyl, and neoprene rubbers. This is a resource that can benefit partners requiring specially formulated compounds for unique applications.

\section{- Compression and Transfer Molding}

Using thermosetting resins such as epoxy, silicone, phenolic, and polyimide, we can perform all types of compression and transfer molding for applications such as housings, brackets, electrical devices, bobbins, and other complex parts.

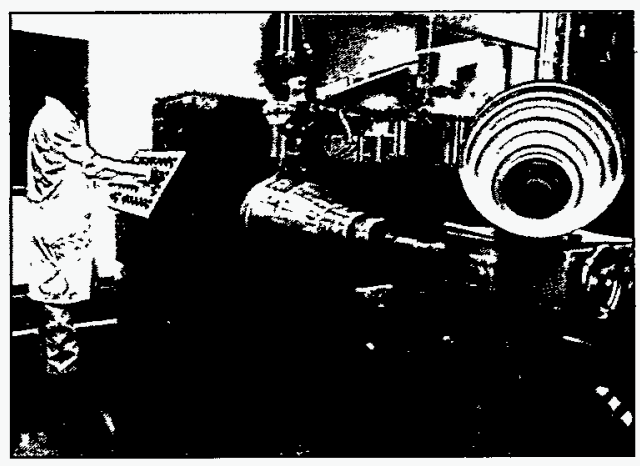

A 5-axis filament winder fabricating a glass/epoxy sunshade.

\section{- Composite Fabrication}

We fabricate polymer composites using hand lay-up, filament winding, and vacuum bagging techniques. These materials are composed of fibers in an organic matrix that can be useful in applications requiring a high strength-to-weight ratio.

\section{- Tooling/Fixture Design}

We design and develop metallic or elastomeric molds and fixtures for a wide variety of product geometries, sizes, and materials; for example, elastomeric seals, adhesive assemblies, foam structures, and intricate encapsulations. 


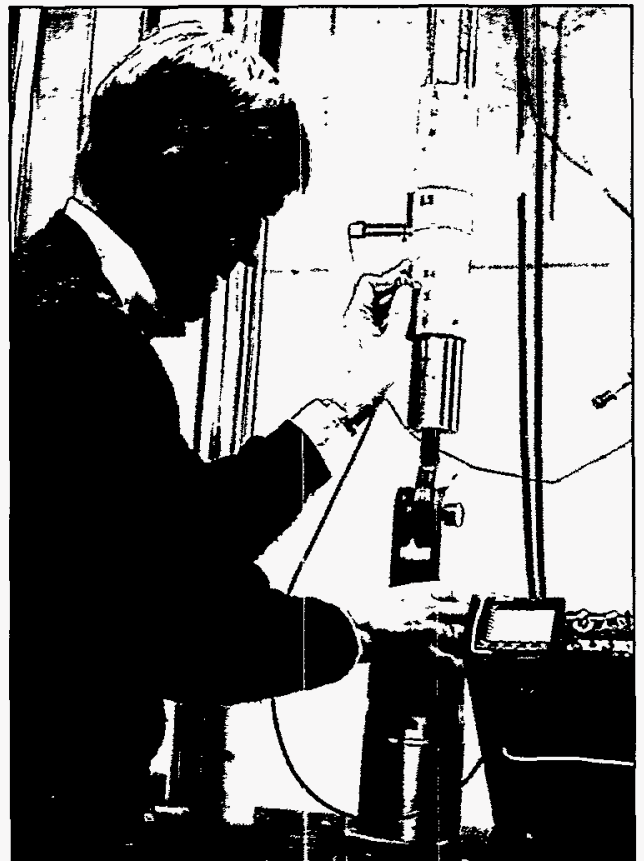

Combined experimental and analytical study of composite-to-metal adhesive bond joints.

\section{Major Resources}

All of our fabrication processes employ the most advanced processing

equipment.

- Abrasive blasters.

- Microprocessor-controlled ovens.

- Autoclaves up to 4 foot diameter $\times 8$ foot long.

- Vacuum casting equipment.

- Thermoformer.

- Rubber mill.

- Computer programmable filament winder.

- Plasma cleaner.

- Terpene-based cleaning system.

- Vacuum laminator.

- Transfer and compression molding presses.

- Class 100 clean bench.

- Gradient cure apparatus.

\section{Selected \\ Accomplishments}

- We developed processes to control the progression of the gel front of an encapsulated assembly by imposing a thermal gradient during cure to minimize cure shrinkage stresses.

- For Sematech, an ultra-lightweight, stiff, photolithographic platform was fabricated by adhesively bonding carbon/epoxy panels and phenolic honeycomb.

- A cyanate ester/fiberglass laminate 3-foot-diameter dome incorporating a flexible PWB antenna was assembled using hand lay-up and vacuum bagging technology and autoclave cured.

- Sunshades for protection of global positioning satellite optics were produced using fiberglass/epoxy prepreg on the five-axis filament winder.

- We developed a vacuum-assisted pressure injection process to encapsulate a tightly wound copper coil, up to 12 inch diameter by 4 inches high using an in-house formulated flexibilized epoxy.

- Surface preparation, primer processing, and unique tooling were developed to line high performance, 16-inch-diameter trolley sheaves (pulleys) with a polyurethane elastomer in order to reduce Kevlar cable abrasion and to enhance trolley braking ability.

For more information, call

John L. Ledman

(505) 845-8544, or

Carla Chirigos

(505) 845-8645. 


\section{Process Analysis Laboratory}

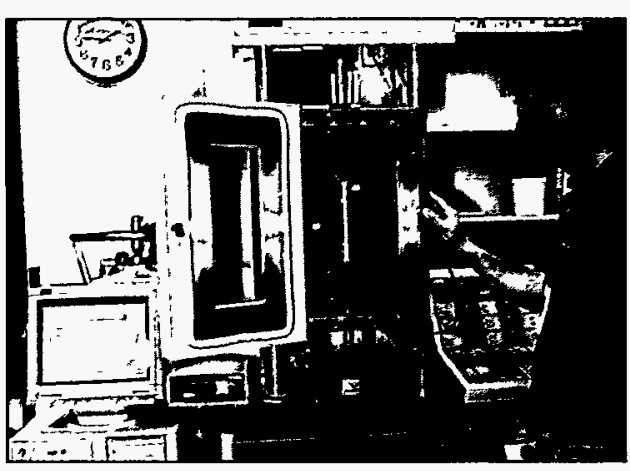

Mechanical testing of environmentally friendly materials.

The Sandia National Laboratories' Process Analysis Laboratory provides expertise and capabilities for a wide assortment of analytical techniques for materials applications. We provide scientists, engineers, and designers with a broad range of chemical and material characterization techniques.

One of the main areas that the Process Analysis Laboratory supports is Environmentally Conscious Manufacturing (ECM). We will work with you to qualify alternative cleaners and materials to replace traditional processes that have been labeled as ozone depleting, toxic, and/or suspected carcinogens.

\section{Capabilities}

- ECM material and process compatibility verification for components, subsystems, and systems.

- Thermal Analysis.

- Experimental Mechanics.

- Spectroscopy.

- Optical and Electron Microscopy.

- Elemental Micro-Volume and Surface Analysis.

- Wet Chemical Analysis.

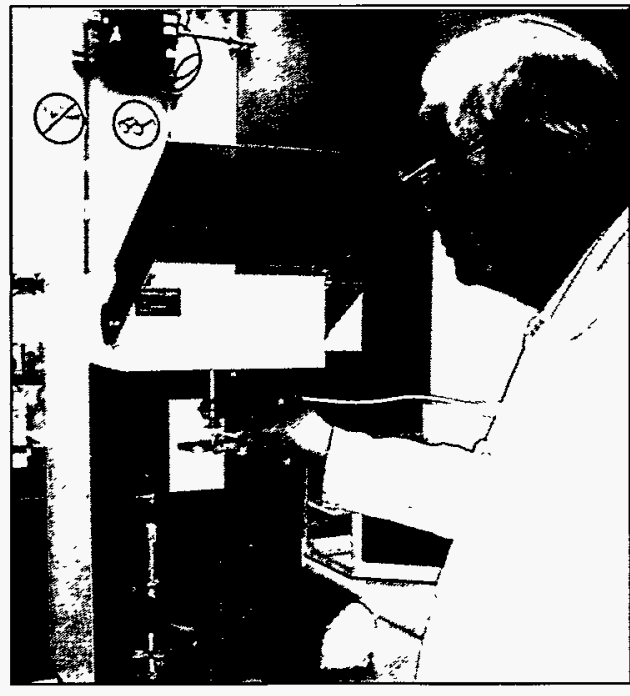

Measurement of thermal properties on ECM materials.

\section{Major Resources}

\section{- Thermal Analysis}

Differential Scanning Calorimeter (DSC), Thermal Mechanical Analyzer (TMA), Thermal Gravametric Analyzer (TGA), Volume Dilatometer, Microdielectrometer, Coefficient of Thermal Expansion (CTE), and Electrical Resistivity. This equipment is used to determine glass transition $\left(T_{g}\right)$, heat capacity $\left(C_{p}\right)$, reaction kinetics, bulk modulus, mass changes as a function of temperature, volume changes, and volume resistivity.

\section{- Mechanical Testing Laboratory} Supports ECM and materials experimental mechanics programs. Test procedures and equipment are available for measuring tension, compression, torsion, shear, peel, flexure, fatigue, and fracture toughness responses of materials and structures. Auxiliary equipment and instrumentation in the mechanical test laboratory includes environmental chambers $\left(-300^{\circ} \mathrm{F}\right.$ to $\left.1100^{\circ} \mathrm{F}\right)$, strain gages, extensometers, Linear Variable Differential Transformers (LVDTs) and laser displacement gages. For rheological testing of polymers and related materials, Dynamic Mechanical Analyzer (DMA) equipment is available for characterizing liquids, melts, and solids. A Micro-Hardness Tester is used to perform material hardness testing.

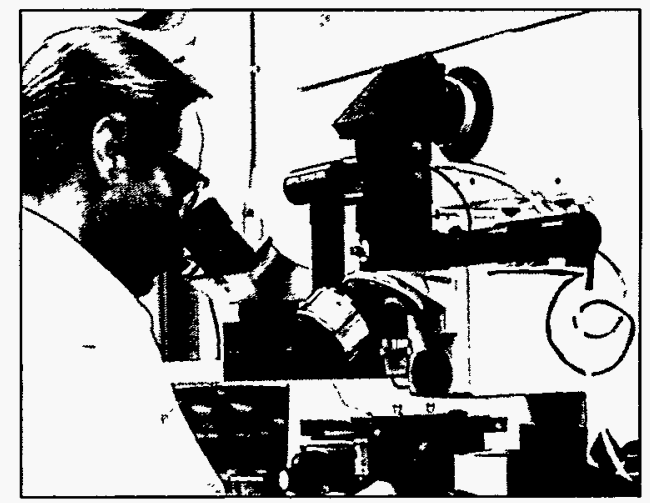

Infrared analysis of polymeric material using microscope accessory.

- Fourier Transform Infrared Spectroscopy (FTIR)

For identification of various materials (polymers, coatings, lubricants, etc.).

\section{- Atomic Absorption (AA)} For identification of metals in solution.

- Optical and Electron Microscopy A full range of macro to $2000 \mathrm{X}$ optical imaging. Complete sample sectioning, potting, diamond-slurry lapping, polishing, and etching. Digital optical image analysis and feature measurement, file transfer and archiving capability. Lanthanum hexaboride $\left(\mathrm{LaB}_{6}\right)$ cathode equipped Scanning Electron Microscope (SEM) with $5.0 \mathrm{~nm}$ or better resolution. Morphology, atomic number, and elemental imaging capabilities. Fully integrated with an Energy Dispersive Spectrometer (EDS) $X$-ray elemental analyzer. Image analysis and digital file archiving and transfer over the Internet. 


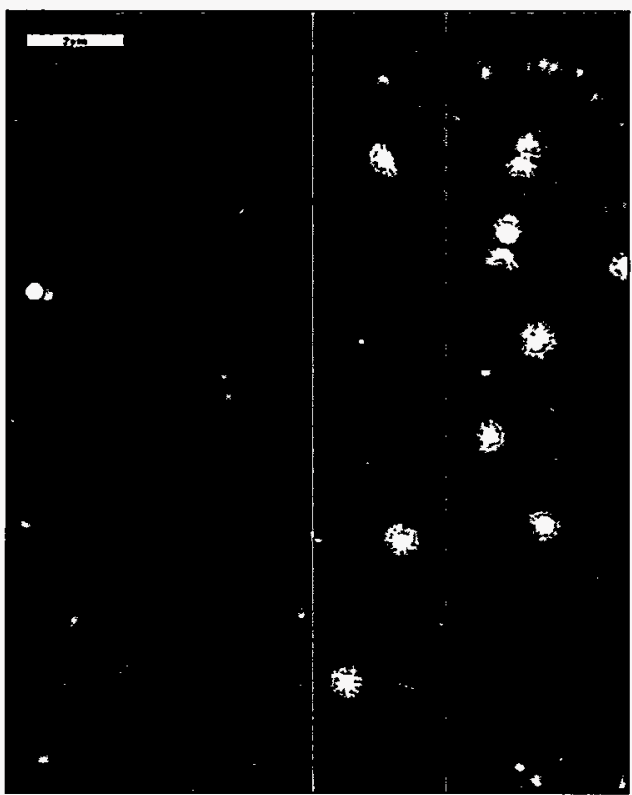

SEM image of silica "Flowers" on copper braze materials.
- Elemental Micro-Volume and Surface Analysis

Near surface and micro-volume analysis using high resolution Germanium X-ray EDS elemental analysis system. Micron level spatial and depth resolution down to elemental Boron. Auger surface elemental analysis using computercontrolled acquisition system. PCbased acquisition systems are able to archive and process digital data.

\section{- Wet Chemical Analysis}

For the determination of various analytes by means of titration and electrochemical measurements.

\section{Selected}

\section{Accomplishments}

- Qualified new cleaners or materials for Vanguard Electronics, Sensitron Semiconductors, and Reynolds Industries, Inc.

- Qualified d-limonene to replace trichloroethane for War Reserve use in electronic assemblies for the DOE.

- Participated in a combined experimental/analytical program to study the behavior of composite-to-metal joints of the type found in wind turbine blades. Developed test methods and performed static and fatigue tests of adhesively bonded tubular lap joints.

- Developed a system to measure volume resistivity of silver-filled epoxies as they cure at elevated temperatures.

- Evaluated lead-free solder through intermetallic growth and microstructure studies to support a Cooperative Research and Development Agreement (CRADA) with NCMS.

- Implemented Volume Dilatometer to support a CRADA with Goodyear for determining bulk volume cure expansion.

- Developed diamond lapping procedure to reduce the amount of pull-out for metallographic preparation of thermal spray coatings that are complicated by the presence of hard/soft materials.

For more information, call

John L. Ledman

(505) 845-8544, or

Carla Chirigos

(505) 845-8645.

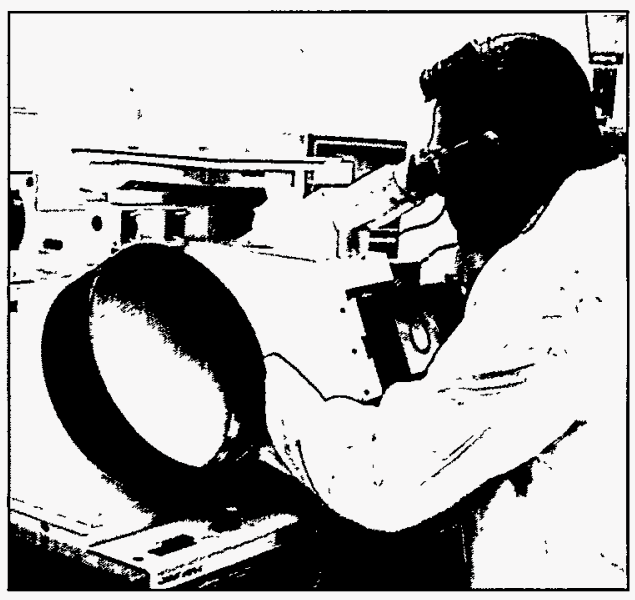

Measurements of plating thickness using optical microscopy. 


Materials

\section{Ceramics}

The Ceramic Processing Laboratory at Sandia National Laboratories provides a wide range of processing options for many types and compositions of prototype ceramic components such as alumina, lead zirconate titanate (PZT), barium titanate, zinc oxide varistor, and superconducting ceramics.

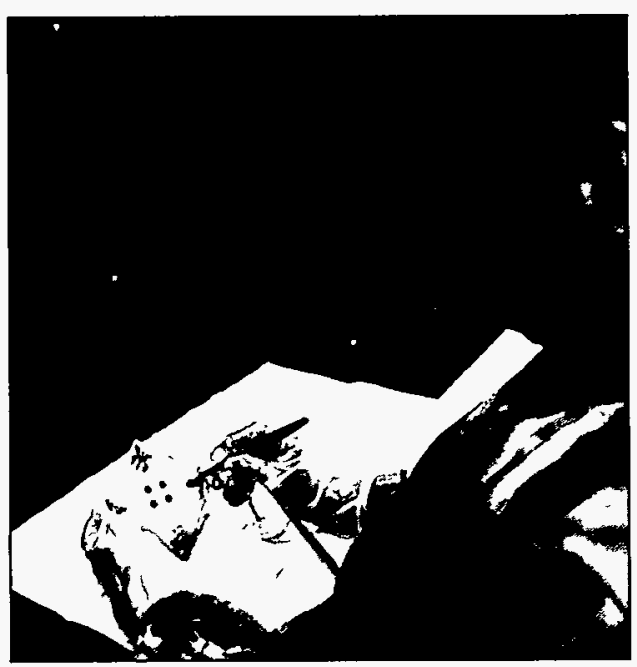

High-quality prototype electronic components are assembled and inspected prior to testing.

\section{Capabilities}

- Formulate and produce tailored polycrystalline ceramic compositions by conventional mixed oxide or by advanced chemical preparation technology.

- Determine key processing parameters related to ceramic powder preparation, consolidation, densification, and assembly to optimize the properties of the final ceramic component.

- Fabricate prototype ceramic components to support the design and test phases of a wide range of projects.

- Interface with designers and ceramic vendors to assure that the most appropriate materials are selected to meet specifications.
- Develop new chemical preparation processes for ceramic powder production.

- Perform process development needed to scale up laboratory research processes.

- Provide production capability and quality processing for ferroelectric ceramics.

- Fabricate prototype alumina structural or insulating components with rapid turnaround time.

- Develop multilayer ceramic-metal devices based on the tape casting of thin ( 0.001 to 0.080 inches) flexible ceramic layers and associated thick film technology.

- Produce fully dense refractory ceramics or composites by hot pressing at temperatures up to $1800^{\circ} \mathrm{C}$ in controlled atmospheres (vacuum, air, or inert gases).

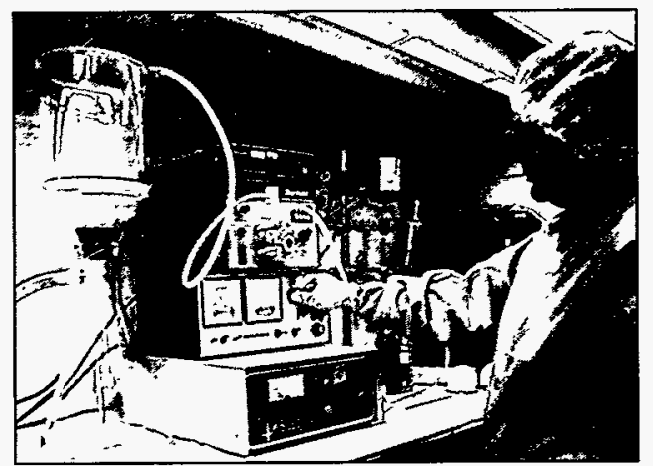

Chemical precipitation of superconducting ceramic powders.

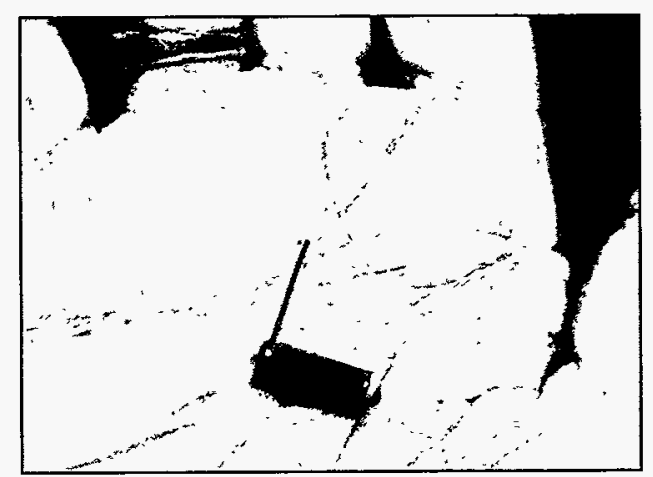

ZnO varistor prepared from powder synthesized by solution precipitation.
- Employ powder consolidation methods such as uniaxial and cold isostatic pressing, slip casting, and colloidal filtration to form ceramic parts.

- Develop processes and fabricate prototypes of ferroelectric thin film components employing sol-gel processing, spin coating, and photolithographic definition.

- Develop precision hermetic electrical feedthrough using a novel alumina/molybdenum composite process (cermets).

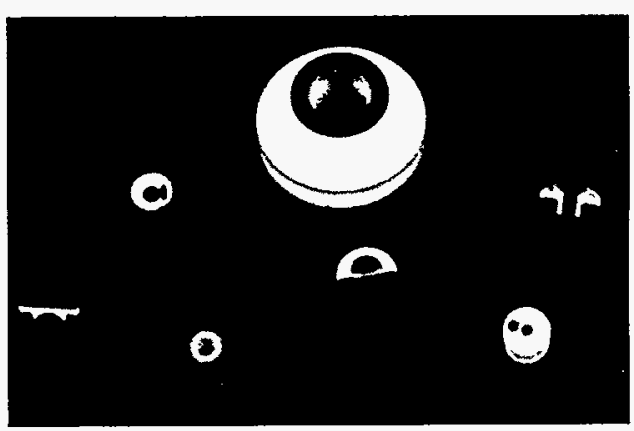

Cermet composites

(alumina/molybdenum) for hermetic electrical feedthrough applications.

\section{Major Resources}

- Four laboratories supplied with HEPA-filtered air and Class 100 down flow hoods.

- Multilayer ceramic processing facility for developing advanced electronic ceramic components.

- Pilot scale ferroelectric component processing facility.

- State-of-the-art powder consolidation equipment, sintering furnaces, and hot presses.

- Prototype ceramic machining and component assembly equipment. 


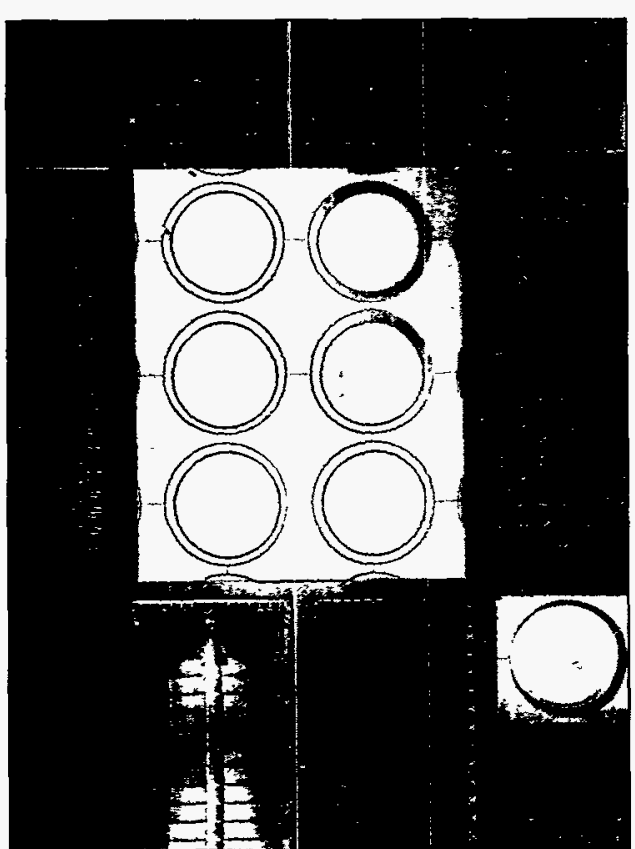

Array of six ferroelectric thin film decoupling capacitors with platinum top electrodes.

\section{Selected Accomplishments}

- Scaled up a laboratory chemical preparation technique for producing zinc oxide varistors into a full-scale manufacturing process. Successfully transferred this process to a commercial vendor.

- Scaled up a continuous precipitation process for preparation of high purity homogenous ceramic super conductor $\left(\mathrm{YBa}_{2} \mathrm{CuO}_{7}\right)$ precursor. This process has been in commercial production for five years.

- Developed an organic, solvent-based process for tape casting of oxide, nitride, metal, and glass powders.

- Developed a process to fabricate aluminum-molybdenum electronic packaging.

- Developed a precision high surface finish metallized alumina to vaporize lithium for particle beam fusion energy experiments.

- Produced small lots of specialized ferroelectric components for the nuclear weapon stockpile.

- Developed prototype lanthanumdoped PZT thin film decoupling capacitors for use in a multi-chip image correlator.

For more information, call

Frank P. Gerstle, Jr.

(505) 845-8337, or

Carla Chirigos

(505) 845-8645. 


\section{GLASS}

The Sandia National Laboratories' Glass Processing Team offers you a wide range of capabilities that let you take advantage of the many special properties of glasses and glassceramics. The Glass Lab is a complete source for formulation, characterization, process definition, and fabrication of high-reliability glass products for any application.

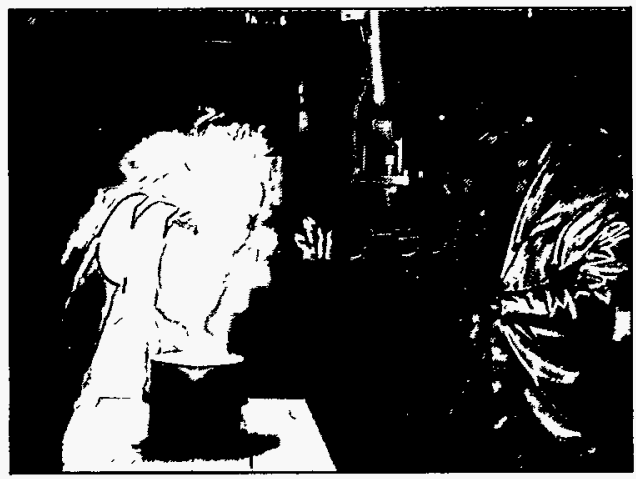

Pouring of specialty glass.

Our products function in extreme environments: corrosion, heat, pressure, and impact. The Glass Lab Team produces highly complex electronic components by combining glass and metals such as titanium, aluminum, and Inconel for unique applications.

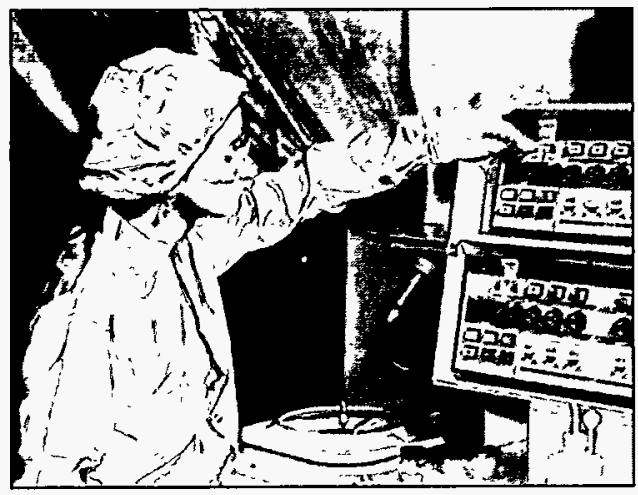

Sol-gel processing.
Once a product has been designed and fabricated, the Glass Lab can evaluate its performance in specific environmental testing conditions. The Glass Lab Team serves as a technical resource to private industry in the areas of glass processing and sealing.

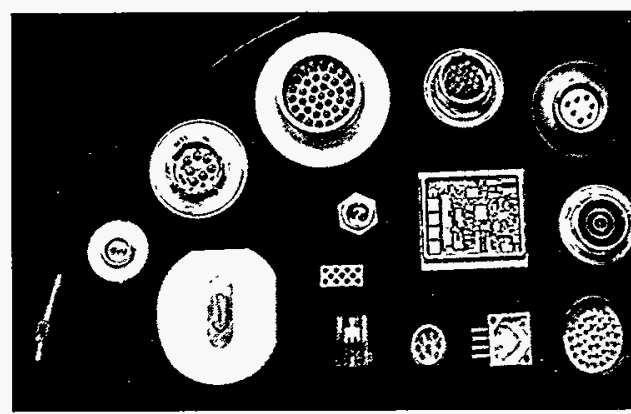

Headers, hermetic feedthroughs and connectors.

\section{Capabilities}

- Formulate and produce glass compositions by conventional hightemperature melting or lowtemperature chemical polymerization (sol-gel techniques).

- Establish key processing timetemperature schedules for annealing, sealing, and crystallization.

- Measure and control residual stresses using photoelastic and fringe measurement techniques.

- Analyze failures and modify manufacturing processes.

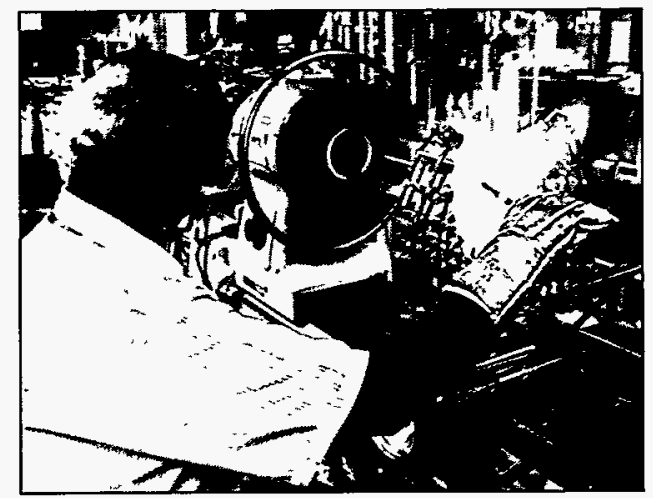

Scientific glassblowing.
- Design seals using computer-aided stress minimization routines.

- Measure physical properties such as coefficient of thermal expansion, density, viscosity, and index of refraction.

- Fabricate a wide range of glass apparatus for electronic, vacuum, and chemical applications including quartz semiconductor glassware.

- Fabricate prototype electronic and specialty components that incorporate glass or glass-ceramic to metal seals.

- Provide a full range of glass forming techniques including casting, pressing, and spinning.

- Chemically strengthen glass to customer specifications.

- Fabricate vacuum glassware, backfill with specified gas, and analyze using mass spectrometry.

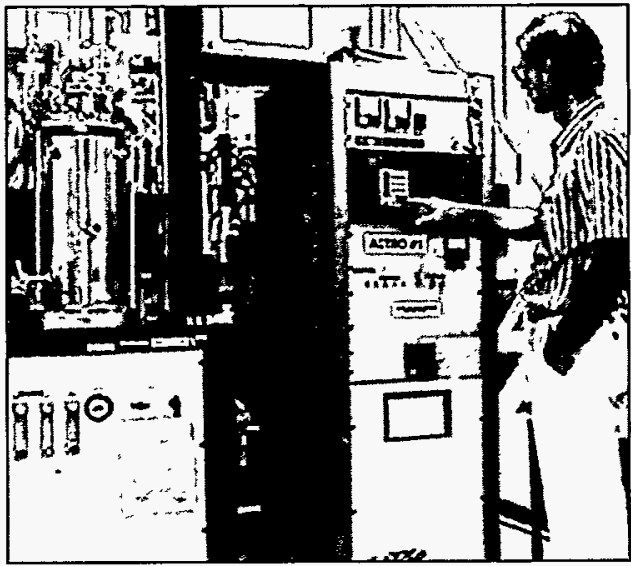

Programming a batch furnace.

- Deposit thin films with controlled porosity using sol gel process.

- Machine ultra-low density glass foams (aerogels) prepared by sol-gel process.

- Perform low-temperature, fieldassisted bonding of glass to specific metals.

- Apply conductive coatings - silver, tin, gold, platinum - by wetchemical and thermal process. 
- Develop glass and glass ceramic headers for components used in severe environments: actuators, batteries, miniature connectors, detonators, fiber optic devices, sensors, and x-ray tubes.

- Produce quality melts of specialized glass compositions, including tellurium and tungsten-based glasses, aluminum sealing glasses based on phosphorus and germanium, and a variety of fluoride glasses.

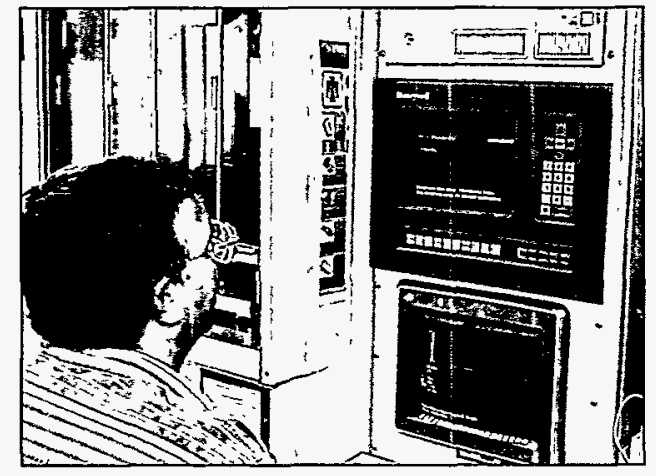

Glass melt monitoring.

\section{Major Resources}

- High temperature $\left(2000^{\circ} \mathrm{C}\right)$ glass melting furnaces.

- Class 1000 clean room for sol-gel applications.

- Microprocessor-controlled batch and moving belt furnaces with controlled atmospheres for glass sealing.

- Glass etching and cleaning stations.

- Full service scientific glassblowing area.

- Precision testing equipment.

- $\mathrm{CO}_{2}$ laser glass sealing area.

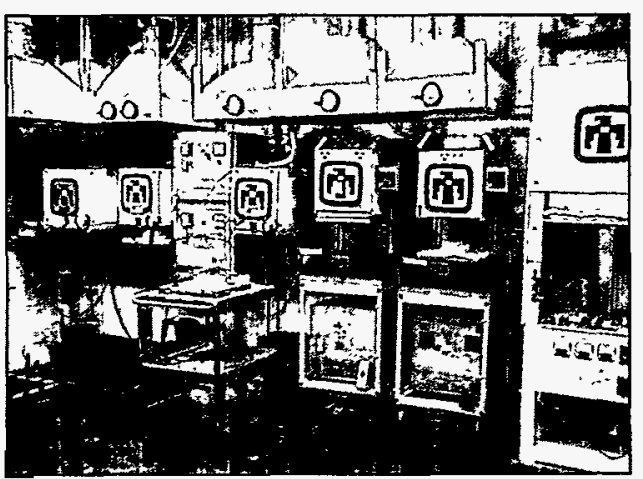

Glass melt furnaces.

\section{Selected \\ Accomplishments}

- Developed sol-gel glass coatings for anti-reflective glass and plastic surfaces for solar energy collectors.

- Invented sol-gel protective coating and an aerogel-phosphor composite for radioluminescent light sources and power applications.

- Invented a family of corrosion resistant sealing glasses for use in ambient temperature lithium batteries.

- Developed novel techniques for making hermetic seals (field-assisted bonding and laser sealing).

- Developed optical feedthroughs for laser diode ignition of pyrotechnics and for single crystal resonators.

- Patented a family of high-expansion, corrosion resistant glasses for sealing to aluminum alloys.

- Developed processes for frit and laser sealing of float glass flat panel displays.

- Manufactured a refractory borosilicate glass composition that consistently met stringent specifications.

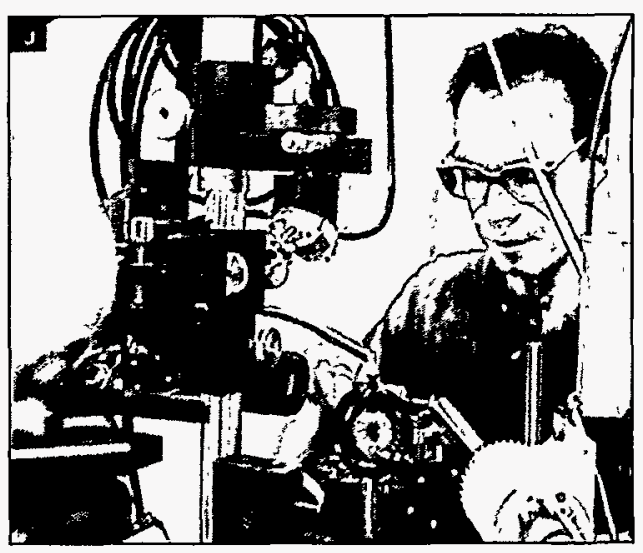

Laser sealing of glass.

For more information, call

Frank P. Gerstle, Jr.

(505) 845-8337, or

Carla Chirigos

(505) 845-8645. 


\section{MACHINING}

The Sandia National Laboratories' Machining group procures, builds, and assembles unique prototype hardware. We assist private sector business as a technical liaison in prototype development. Our team's expertise includes: precision machining, component fabrication and assembly, aircraft quality sheet metal construction, and explosives machining and assembly.

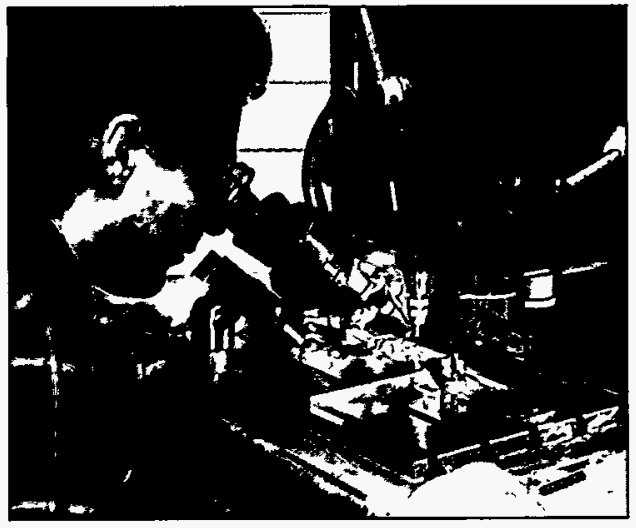

Machining a miniature part requiring use of a microscope.

We can work with your engineers to transform sketches and ideas into working prototypes. Our extensive experience in prototype development enables us to help keep costs down and provide quick turnaround. An extensive array of equipment enables us to manufacture your design into a viable prototype. Our project management is tailored to your requirements. We can provide project planning (Gantt and PERT), special detailed cost tracking, and unique quality assurance and documentation, for example, ISO-9000.

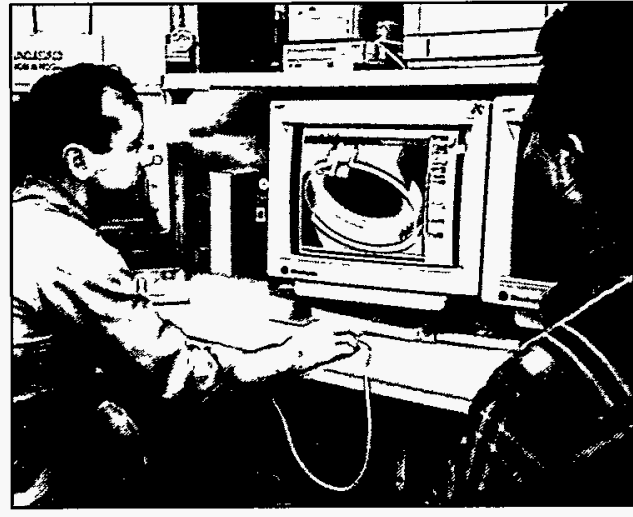

Computer graphic representations are employed to verify Computer Numerically Controlled (CNC) programs quickly and accurately. Solid modeling and color shading provide visual clues about feed rates, potential part gouging, and interferences.

\section{Capabilities}

\section{- Paperless Processing}

Our Numerical Control (NC)

programming team accepts

Pro/Engineer models as input to the manufacturing process. Team members use Pro/Manufacture to program NC lathes, milling machines, and a sheet metal punch. Pro/Engineer files are transferred electronically from the designer, eliminating traditional drawings.

\section{- Project Machining}

Provide project management and manufacturing services to produce R\&D hardware, test fixtures, and laboratory equipment.

\section{- Miniature Machining}

Start-to-finish fabrication of very complex miniature $(0.0002$ inches tolerance) mechanisms.

\section{- Heavy Machining} Large computer-controlled machines to fabricate and assemble prototype hardware that exceeds 12 inches in diameter or 18 inches in length.
- Composites and Surface Finishing

Lapping and polishing to micro-inch finishes and flatness, precision grinding of exotic materials (such as quartz, sapphire, boron nitride, and tungsten), and machining composite materials (such as carbon, silica phenolic, and fiberglass).

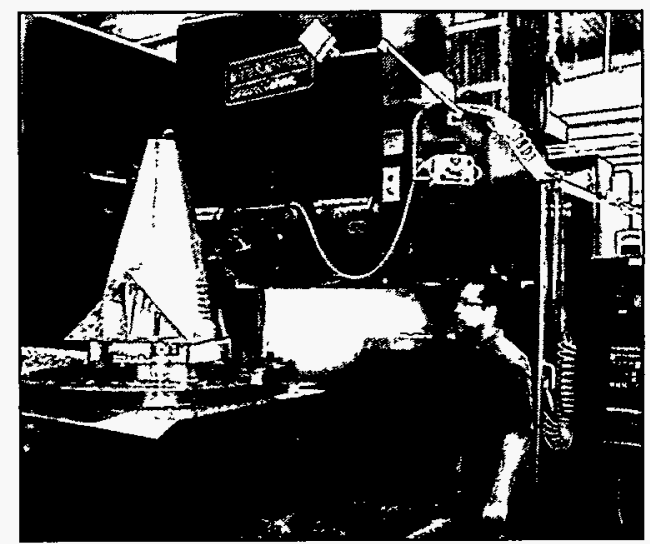

Five-Axis machining center used to fabricate flight test cone for strategic defense command.

\section{- Sheet Metal and Welding} Fabricate a variety of complex, precision assemblies and components such as rocket bodies, re-entry vehicles, and hot metal forging. Provide mechanical assembly services. Design and fabricate special tooling and fixtures to meet customer requirements. Provide structural and pressure vessel welding.

\section{Major Resources}

\section{- Project Machining}

Numerically Controlled (NC) milling machines, lathes, and wire-cut Electrical Discharge Machines (EDMs). Our large wire EDM is one of the few five-axis EDMs located in North America. Our four-axis state-of-the-art EDM sinker is fully NC programmable and will accommodate parts up to 8 inches $\times 17.7$ inches $\times 8$ inches. 


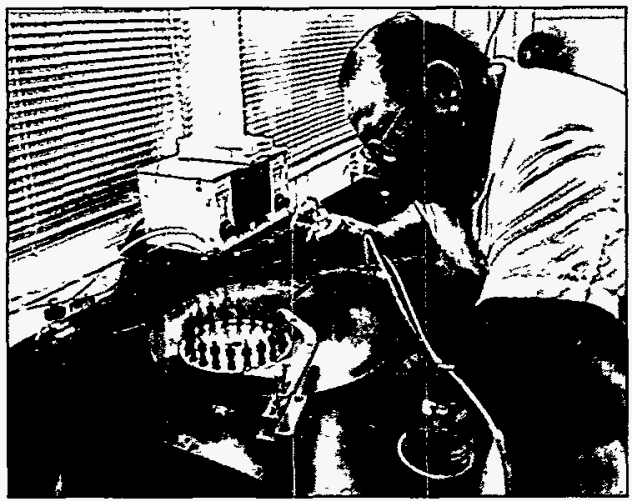

Lapping several fiber optic cables.

\section{- Miniature Machining}

CNC milling machines, jewelers' and $\mathrm{CNC}$ lathes, jig bores, ram and wire EDMs.

\section{- Heavy Machining}

Three-, four-, and five-axis machining centers. Large lathes and boring mills.

\section{- Sheet Metal and Welding} CNC punch press, shears, press breaks, power rolls, power forging hammer; shielded metal arc, gas tungsten arc, gas metal arc, and portable welders.

\section{- Explosive Machining} Lathe, milling machines, and hydraulic presses. This equipment is modified for machining of explosives and has controls for remote operation.

\section{- Composites and Surface Finishing}

Surface grinders (capacities from 6 inches $\times 8$ inches to 36 inches $\times 96$ inches), outside diameter and inner diameter grinders, universal grinders (capacities from 0.050 to 30 inches in diameter), and honing machines. State-of-the-art equipment includes $\mathrm{CNC}$ jig grinders (for grinding complex configurations in a wide variety of materials), lapping and polishing machines, and verification inspection equipment.

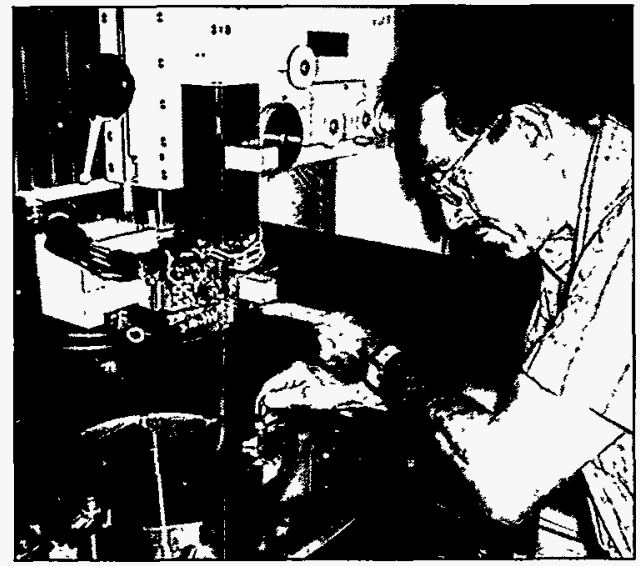

Traveling wire Electrical Discharge Machining of fine features in steel blank.

\section{Selected Accomplishments}

- Provided rapid response for building flight hardware including replica decoys, spin tables, and rocket adapters.

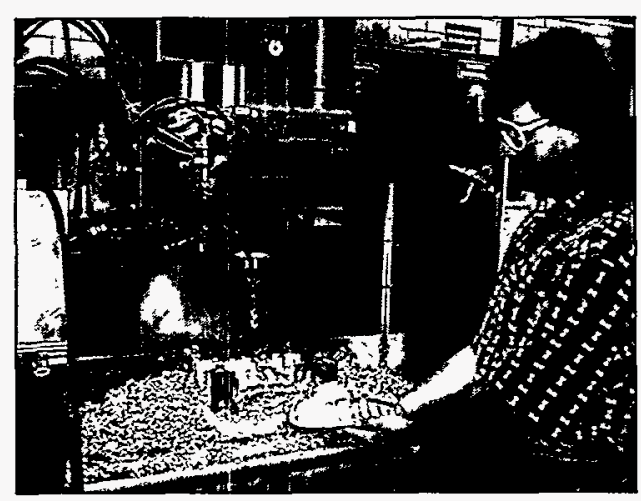

Fabrication of $45 \mathrm{GHz}$ reflector directly from Computer Aided Design model on 3-Axis Computer Numerically Controlled machine.

- Supported the Midcourse Space Experiment (MSX) project throughout design, development, and fabrication phases.

- Fabricated two flight test reentry vehicles including the substructure, cover, and nose parts.
- Fabricated unique and precise hardware for satellite applications.

- Fabricated quartz antennas for prototype testing.

- Polished fiber optics for arming devices.

- Machined ceramic components for neutron tube development.

- Fabricated and assembled two Space Power Unit Reactors requiring support throughout design, fabrication, and installation phases.

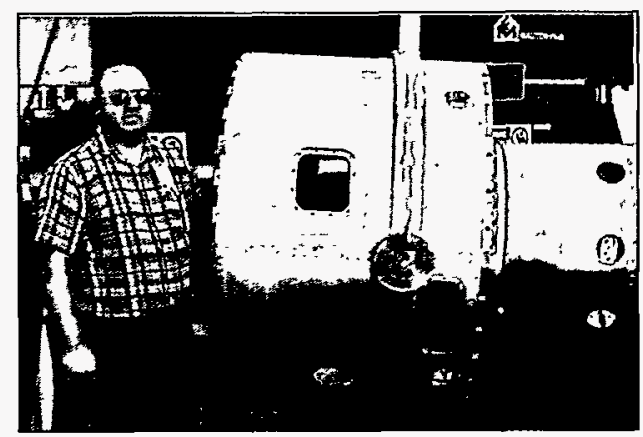

Precision sheet metal tradesman with rocket payload body.

For more information, call

Paul W. Plomp

(505) 844-4307, or

Tommy M. Simpson

(505) 844-1341. 


\section{Measurement and Calibration}

When the application requires exacting mechanical measurements, the stateof-the-art equipment and skillful technicians of Sandia National Laboratories' Measurement and Calibration teams offer a full range of measurement and calibration expertise. We perform complex geometry characterization of known and unknown geometries to accuracies within millionths of an inch and 0.2 arc seconds in a precisely controlled temperature laboratory.

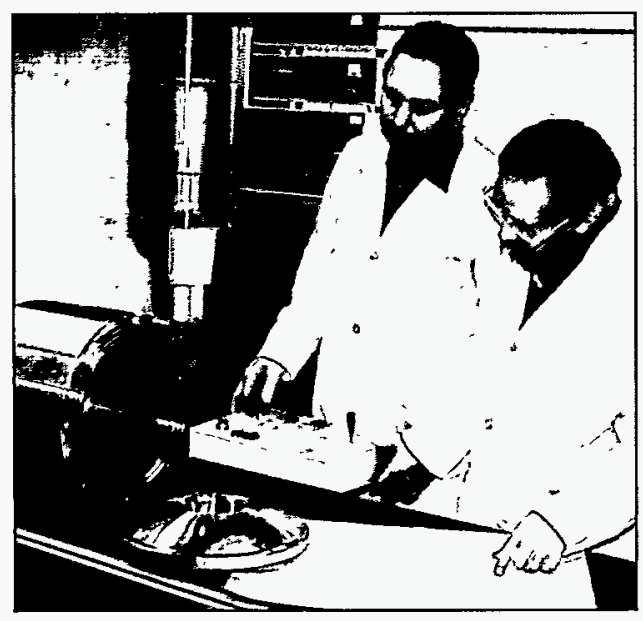

Measurement technicians consult on drawing interpretation and measurement technique.

\section{Capabilities}

\section{Measurement}

- In-process and final dimensional measurements from miniature components to large structures.

- Pre-testing and post-testing measurement data of containers and test hardware for the Nuclear Regulatory Commission.

- Complex geometry characterization of known and unknown geometrics to accuracies within millionths of an inch.
- Measurement consultation and engineering drawing interpretation assistance of dimensioning and tolerancing in accordance with ANSI Y14.5M.

\section{Calibration}

- Calibration of length, mass, force, and dimensional reference standards.

- Precision dimensional measurements to microinches, micrograms and 0.2 arc seconds in a $68^{\circ} \mathrm{F}$ temperature controlled lab.

- Linear, profile, roundness, surface texture, force, and optical measurements.

- Direct Computer Numerically Controlled programmable measuring capabilities.

- Data collection and sampling for statistical process control.

- Provided alignment and precision measurements on a continuing basis for satellite components.

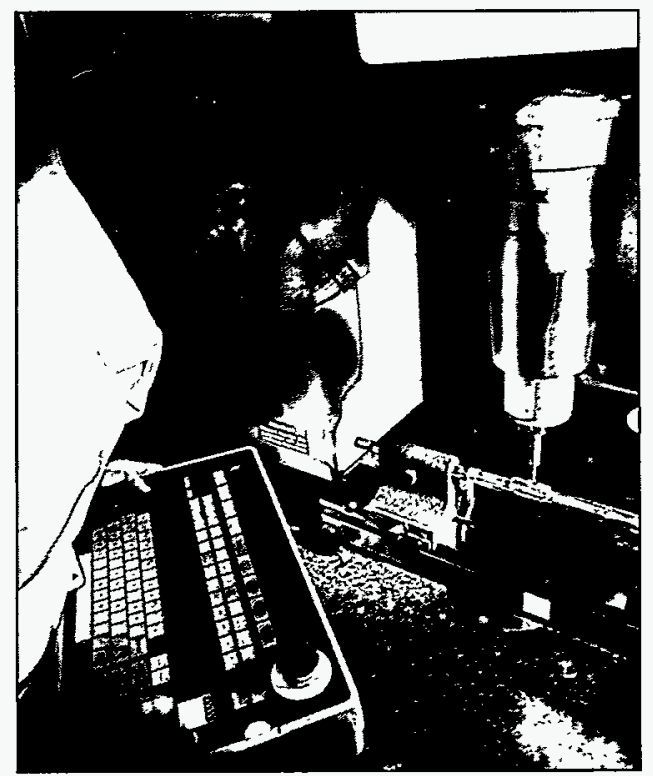

Precision measurement of flute mouth piece using a Coordinate Measuring Machine.

\section{Major Resources}

\section{Measurement}

- Coordinate Measuring Machines (CMMs):

- Mauser KMZ 201210 (measuring envelope of 78 inches $x 47$ inches $\mathrm{x} 39$ inches).

- Zeiss MC 550.

- Zeiss UPMC 550 with a resolution of 0.000008 inches.

- Portable CMM with a six foot diameter measuring envelope.

- Formscan 3000 roundness machine.

- Thirty-inch optical comparator with a rotary table.

- Lietz universal measuring microscope.

- Federal Surfanalyzer System 2000.

- Deep bore diameter electronic gauging ( $1 / 2$ to 17.9 inches diameter range and up to 40 foot depth range).

- Wilson hardness testers.

- Non-contact laser measuring system.

- Optical video inspection system.

- Precision pins in 0.0001 increments (.004 inches to 1.0120 inches).

- Ultrasonic thickness testers.

- Straightness measuring system.

- Theodolites.

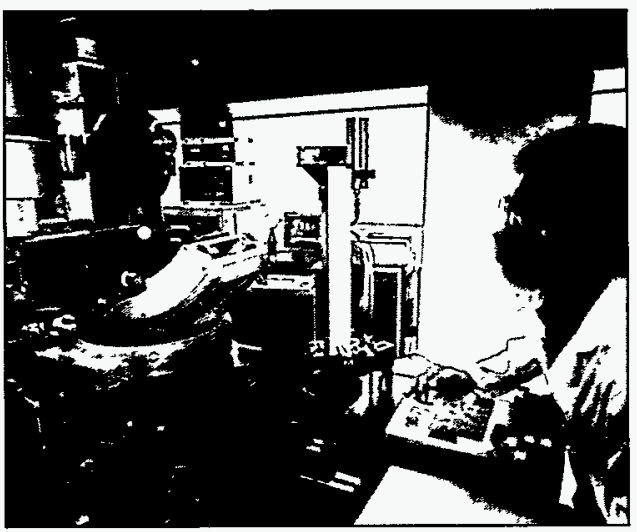

Precision alignment of a seven positioning goniometer using a Coordinate Measuring Machine. 


\section{Calibration}

- Zeiss Universal Precision Measuring Center (UPMC) 550 CMM.

- Non-contact profile acquisition system.

- Universal measuring machine.

- Thirty-inch optical comparator.

- Surface finish analyzer.

- Zeiss precision microscope.

- Sheffield Indiconder (roundness machine).

- Gage measuring center.

- Analytical balances.

- Federal gage block comparators.

- Spring and force testers.

- Pertlometer non-contact surface analyzer.

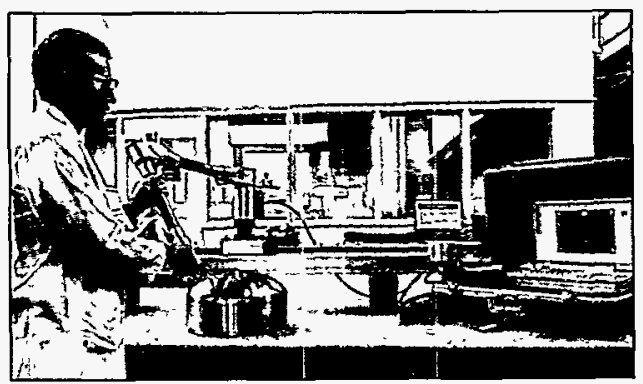

Portable Coordinate Measuring Machine used to scan an ellipse on a vessel component.

\section{Selected}

Accomplishments

\section{Measurement}

- Provided in-process and final inspection, test measurement data, and quality documentation of manufactured parts and assemblies for H1616-1 and H1616-2 shipping containers.

- Provided flatness characterization of a 40 foot $x 40$ foot Helio-Stat for the $60 \mathrm{~kW}$ solar furnace.

- Provided in-process and final measurements with graphic documentation of a precise wind tunnel model.

- Provided 0.001 tolerance profile measurement on complex neutron tube hardware.

\section{Calibration}

- Provided dimensional verification of the process and parts produced in our rapid prototyping lab by stereolithography and selective laser.

- Provided field measurements and calibration of underground test frames at the Waste Isolation Pilot Plant site.

- Instrumented a centrifuge with a Helium Neon laser optics system which assisted in the dynamic calibration of MC3813 force balance integrating accelerometers at a force of $125 \mathrm{~g}$ 's.

For more information, call

Paul C. McKey (505) 844-9412, or

Jon W. Munford

(505) $845-9688$

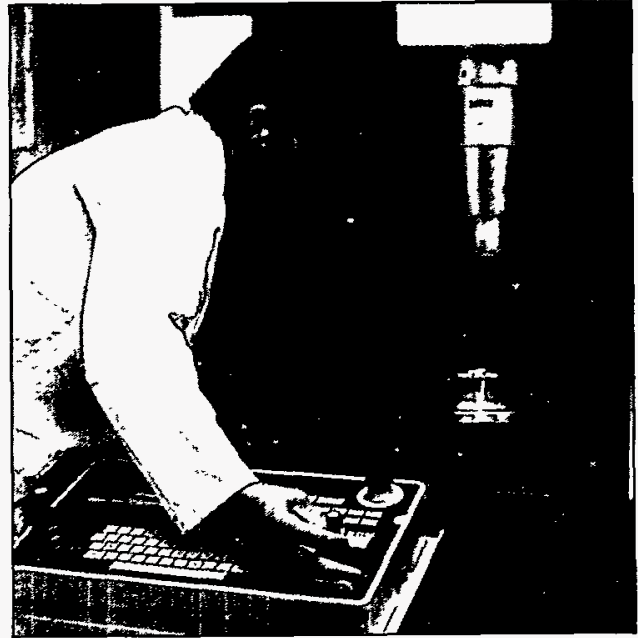

Scanning H1616-1 hardware with a UPMC 550 Coordinate Measurement Machine. 


\section{MANUfACturing EnGINEERING}

The Manufacturing Engineering team at Sandia National Laboratories offers design, process development, piece part fabrication, and assembly of prototype precision components such as small, high-accuracy electromechanical assemblies, high-energy capacitors, neutron generators, and rolamites.

We have provided state-of-the-art winding technology to fabricate and assemble prototype capacitors using fully automated winding machines, designed and built at Sandia.

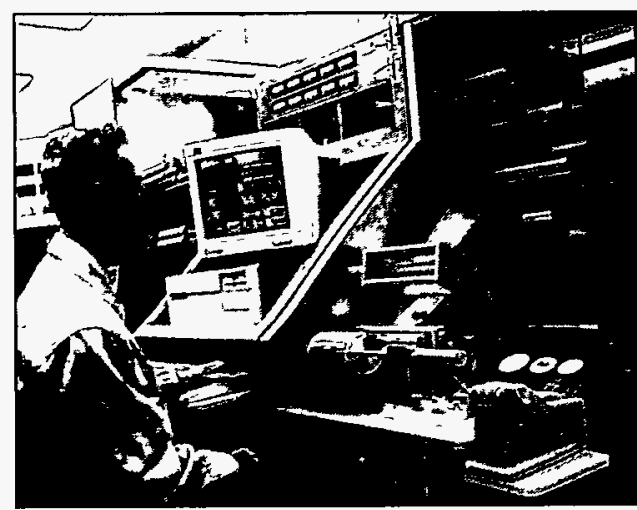

Sandia-designed and-built fully automated winding machine.

\section{Capabilities}

- High-energy density (electron beam, laser, etc.) and conventional welding processes with a full range of inspection and testing capabilities.

- Production of precision investment castings in complex shapes from a variety of alloys, including vacuumcast and precipitation-hardened stainless steels.

- Rapid prototyping processes for manufacture of complex models and prototypes.

- Extensive design and manufacturing expertise for conventional and unique electro-mechanical products.

- Complete project management including design, manufacturing review, cost analyses, fabrication, testing, and inspection.

\section{Major Resources}

- Computer-controlled electron beam, $\mathrm{CO}_{2}$ and solid-state laser welders.

- Precision wire feeder of 5 to $10 \mathrm{mil}$ diameter wire for high-energy density welding.

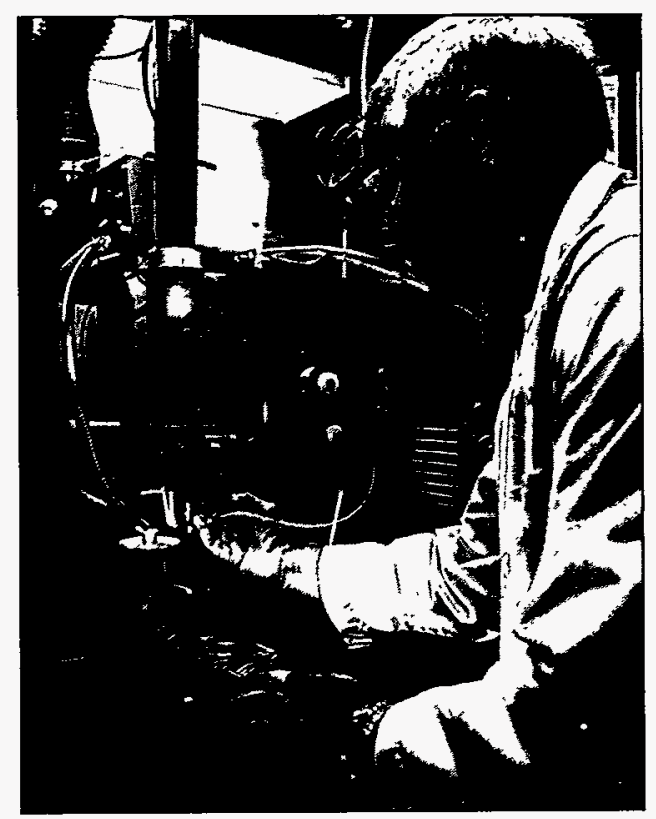

$\mathrm{CO}_{2}$ laser with Sandia-patented and -licensed precision wire feeder.

- A full range of metallurgical processing equipment: furnaces (air, inert gas, vacuum fluidized bed, and salt baths), quench tanks, and large sandblast room.

- Complete machine shop including three-, four-, and five-axis Computer Numerically Controlled (CNC) milling machines, Electrical Discharge Machines (EDM), jigs, bores, lathes, milling machines, and grinders.

- Class 1,000 and 100,000 clean rooms equipped with winding machines, $\mathrm{x}$ ray machine, resistance welder, Instron tester, and microscopes for microphotography for assembly and testing of miniature components and electromechanical devices. Also, several class 100 clean room benches.
- Engineering Laboratory equipped with ultrasonic welder and cleaner, leak detectors, and plasma oven.

- On Machine Acceptance (OMA) program that allows in-process and final inspection by real-time comparison of $\mathrm{x}, \mathrm{y}$, and $\mathrm{z}$ point data to the designers' solid model.

\section{Selected \\ Accomplishments}

- Received patent for precision wire feeder for use with $\mathrm{CO}_{2}$ laser welder.

- Developed fixturing and electron beam weld processes for fabrication of 1 mil tantalum foil envelopes.

- Established a prototype development lab for ferroelectric neutron generators to support reconfiguration transfer activities. The transfer of the prototype development capabilities to Sandia enables the design engineers to work more efficiently with the development of a new generator.

- Fabricated, assembled, and evaluated prototype and development of electromechanical safing and environmental sensing devices. This included fabrication and evaluation of over 300 miniature precision springs.

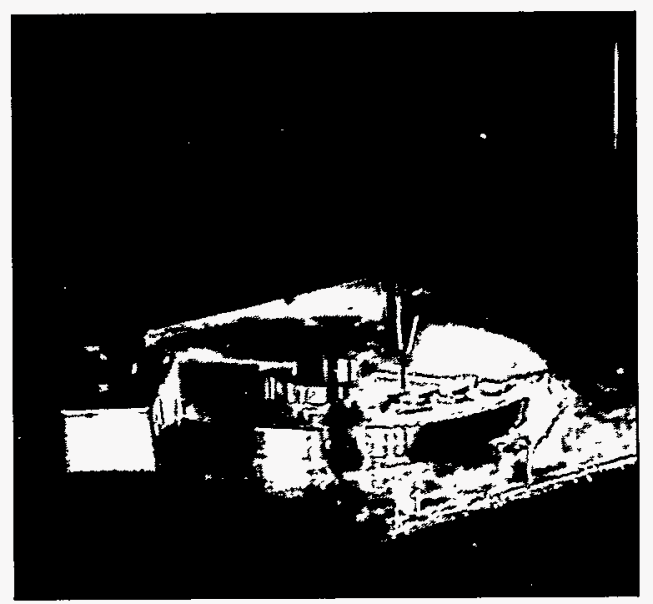

On Machine Acceptance (OMA) in progress. 


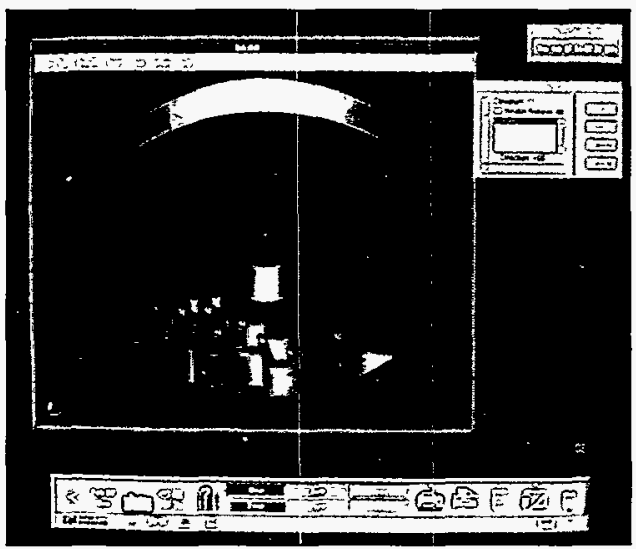

Three-dimensional model with data points superimposed.

- Developed a system for On Machine Acceptance (OMA) to inspect machined parts on the production machine and deliver the inspected and qualified parts to the customer directly from the machine tool. The system will have a tremendous impact on CNC machined part producers of small lot sizes ( $1-50$ parts), by reducing dedicated inspection, scrap, and turnaround time. We have integrated a system that uses the design model to generate the machining path, the probing path, and provide the basis for the inspection data analysis or softgaging.
- Latest generation of capacitor winding system featuring a personal computer-based open architecture control system. Closed-loop tension control for 10 individual winding spindles without the use of clutches, brakes, and couplings. Spindles are controlled by real-time force feedback, over a range from 20 to 500 grams. Software for precise control of material velocity, acceleration/deceleration performance, and speed optimization. Advanced Windows-driven human interface, designed specifically for winding applications, drives the system. Improvements in user friendliness and system simplicity are noteworthy.

- Concurrent engineering utilizing Interactive Collaborative Engineering (ICE) software that enables linking workstations which simultaneously work on designs in different locations.

- Developed an application laboratory using Sandia software called Multi-Dimensional Useroriented Synthetic Environment (uuse) which allows experiencing data in a virtual environment.

For more information, call Jon Munford (505) 845-9688, or

Carla Chirigos

(505) 845-8645 


\section{RAPID PrototyPING}

Rapid prototyping uses advanced computer and laser technology to develop physical prototypes in a fraction of the time of conventional technology. The advantages of rapid prototyping are numerous:

- Optimize design before commitment to hard-tooling.

- Reduce cost and lead time in product realization cycle.

- Produce prototype models more efficiently and quickly.

- Quickly provide high quality patterns for investment casting.

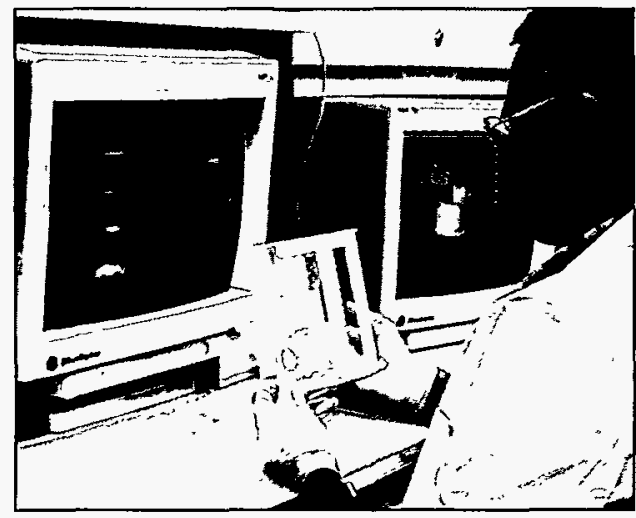

Stereolithography is used to speed-up the product realization process.

Sandia National Laboratories currently has two rapid prototyping technologies in the Rapid Prototyping Laboratory (RPL) - Stereolithography (SLA), and Selective Laser Sintering (SLS).

Currently, the RPL supports internal design and manufacturing efforts at Sandia. The RPL works closely with the FASTCAST consortium to improve the quality of Rapid Prototyping patterns for investment casting by building a basic "tool kit" for the investment casting industry that will replace the expensive "cut and try" methods of mold-making.

Stereolithography is used in the design iteration process to manufacture proofof-concept models, hands-on models for design reviews, and fit-check models. The SLA process is also used to fabricate patterns for investment casting using QUICKCAST ${ }^{\mathrm{M}}$ resin and software. SLA models are used as functional parts in assemblies.

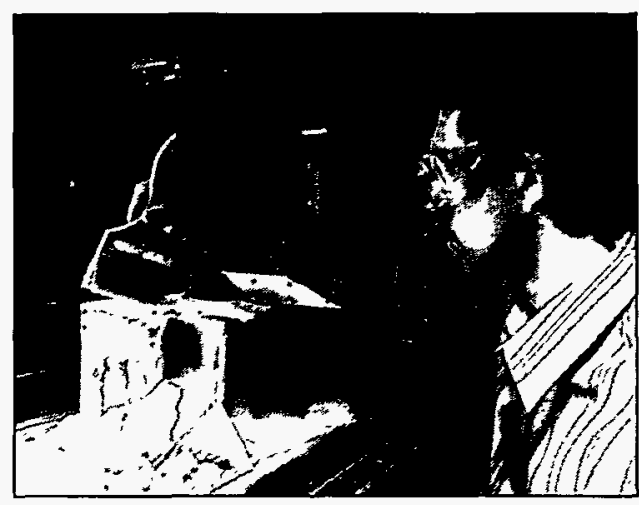

Laser sintering rapidly manufactures patterns for investment casting.

Selective Laser Sintering (SLS) is used to fabricate wax and polycarbonate patterns for investment casting. The SLS process is also capable of manufacturing parts from other materials such as nylon, filled nylon, and polymer coated metal powder.

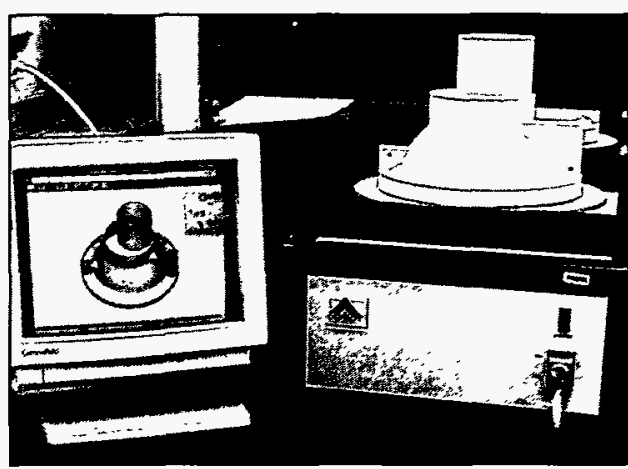

Three-dimensional, 4-axis laser digitizing system.

\section{Capabilities}

- Ability to manufacture physical model and patterns from CAD solid model.

- Prototypes vary in size from miniature to a maximum size of 20 inches $\times 20$ inches $\times 23$ inches.
- Stereolithography materials include acrylic polymer, vinyl ether, and epoxy.

- Selective Laser Sintering materials include polycarbonate, investment casting wax, nylon, glass filled nylon, polymer coated metal powders.

- Produce complex models as visual aids for manufacturing.

- Create hands-on models for design reviews and fit-checks.

- Rapidly turn-around QUICKCAST ${ }^{\mathrm{TM}}$ and complex investment casting patterns.

- Three-dimensional laser digitizing system.

- Investment casting, thermal spraying, numerically controlled machining, precision machining, and plating are additional capabilities.

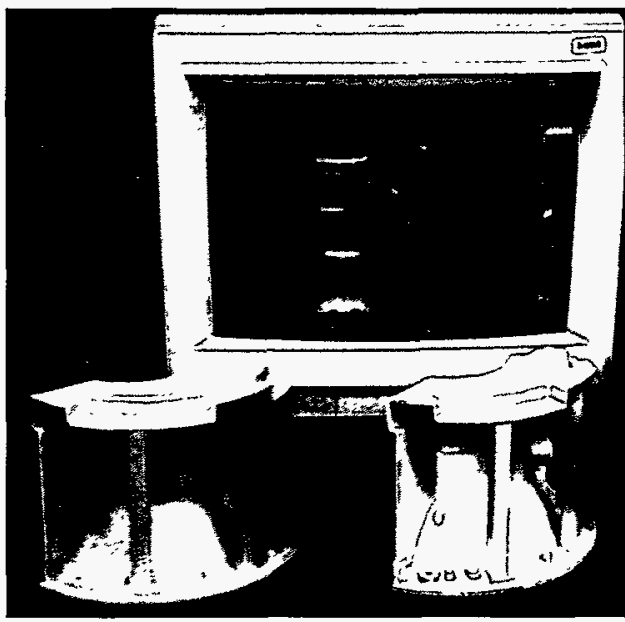

From $C A D$ model to finished part.

\section{Major Resources}

- Silicon Graphics workstations with ProEngineer software.

- DTM Selective Laser Sintering machine - Sinterstation 2000.

- 3D Systems Stereolithography machines models SLA250 and SL500. 


\section{Selected}

\section{Accomplishments}

- Through technology transfer, we helped a New Mexico small business design and build titanium bicycle crank arms. From drawings we generated a CAD file and built an SLA model for verification. We improved the design, built a second SLA model for final verification, and provided three SLS patterns for the titanium investment castings. The private industry partner received leadingedge technology support resulting in a quality product with rapid turnaround.

- Produced prototypes of Direct Optical Initiation housings. The models were used in design reviews. Product realization cycle time was reduced significantly (from several months to three weeks).

- Participated as an Alpha and Beta site for new rapid prototyping machines, hardware, and software to verify reliability and performance before commercialization.

For more information, call Jon Munford (505) 845-9688, or Carla Chirigos (505) 845-8645. 


\section{Mechanical/Electronic Manufacturing Liaison}

The Sandia National Laboratories' Manufacturing Liaison Department offers a variety of electronic and mechanical hardware fabricate-to-print services. Our highly skilled personnel team with industry suppliers and colocated purchasing agents to provide complete project management.

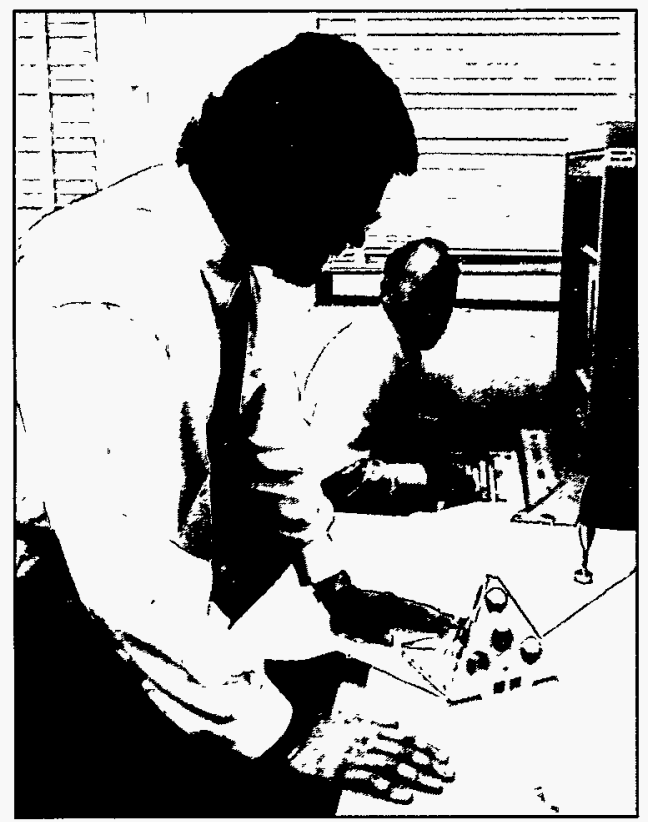

Technical fabrication coordinators discussing fabrication options for a satellite tetrahedron.

\section{Capabilities}

- Drawing reviews for manufacturability.

- Cost estimates.

- Fabrication source suggestions based on supplier capability and demonstrated performance. Supplier rating to assist in source selection.

- Supplier surveys.

- Supplier manufacturing process support.
- Prototype and production project management.

- Fabrication process consultation.

- Electronic design data transfer capabilities.

- Formal geometric dimensioning and tolerancing classes for suppliers.

\section{Major Resources}

- Staff knowledgeable in diverse manufacturing processes. This asset contributes to our success in fabricating a wide variety of rapid turnaround and production hardware.

- Network of capable suppliers ranging from small electronic and machine shops to large multi-task technologically advanced agile manufacturing centers.

- Experience in managing a variety of activities including design, design modification, fabrication liaison, and records management.

- A team of skilled purchasing agents specifically trained in the procurement of fabricate-to-print hardware works closely with Manufacturing Liaison personnel to obtain hardware at an economical cost.

- Continuous communication with the customer and supplier throughout the product realization process.

- Organized capability database of over 2000 vendors.

\section{Selected \\ Accomplishments}

- Coordinated the fabrication of over 2500 H-1616 tritium shipping containers including containment vessel forging for machining special stainless steel drums, stainless steel liners, intumescent foam, packing, and insulating material. Used diverse manufacturing skills to solve all problems and track the project.
- Coordinated the fabrication and inspection of a series of stand-off bomb wind tunnel test models.

- Selected sources and coordinated the fabrication of eight $1 / 4$ scale test trailers for the safe transportation of hazardous materials.

- Supplied a variety of precision miniature machined parts for the MC4277 neutron tube to support weapon research and development.

- Provided various mock-ups of aircraft parts for the aging aircraft studies, which resulted in improved aircraft inspection techniques.

- Continuously provide satellite hardware of complex geometrical shapes from solid stock to $+/-0.001$ tolerances.

- Coordinated the fabrication of 65,000 piece parts of sheet metal to retrofit Russian rail cars for the safe transport of hazardous material. Project completed in one year and $\$ 75,000$ under budget.

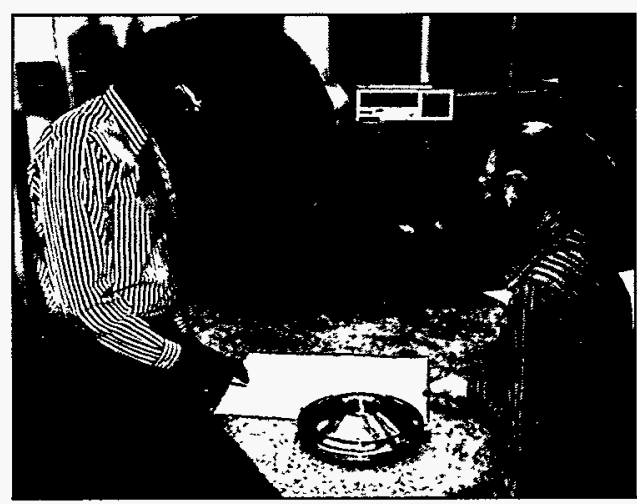

Liaison personnel discussing manufacturing and inspection processes of an H-1616 shipping container.

For more information, call

Paul C. McKey

(505) 844-9412, or

Carla Chirigos

(505) 845-8645. 